\title{
Cholinergic Modulation of Frontoparietal Cortical Network Dynamics Supporting Supramodal Attention
}

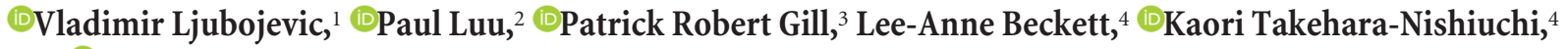 \\ and 1 Eve De Rosa ${ }^{5}$ \\ ${ }^{1}$ School of Medicine, ${ }^{2}$ Department of Pharmacology, University of Toronto, Toronto, Ontario M5S 1A8, Canada, ${ }^{3}$ Rambus Labs, Rambus Inc, Sunnyvale, \\ California 94086, ${ }^{4}$ Department of Psychology, University of Toronto, Toronto, Ontario M5S 3G3, Canada, and ${ }^{5}$ Department of Human Development \\ and Human Neuroscience Institute, Cornell University, Ithaca, New York 14853
}

A critical function of attention is to support a state of readiness to enhance stimulus detection, independent of stimulus modality. The nucleus basalis magnocellularis (NBM) is the major source of the neurochemical acetylcholine (ACh) for frontoparietal cortical networks thought to support attention. We examined a potential supramodal role of ACh in a frontoparietal cortical attentional network supporting target detection. We recorded local field potentials (LFPs) in the prelimbic frontal cortex (PFC) and the posterior parietal cortex (PPC) to assess whether ACh contributed to a state of readiness to alert rats to an impending presentation of visual or olfactory targets in one of five locations. Twenty male Long-Evans rats underwent training and then lesions of the NBM using the selective cholinergic immunotoxin 192 IgG-saporin $(0.3 \mu \mathrm{g} / \mu \mathrm{l}$; ACh-NBM-lesion $)$ to reduce cholinergic afferentation of the cortical mantle. Postsurgery, ACh-NBMlesioned rats had less correct responses and more omissions than sham-lesioned rats, which changed parametrically as we increased the attentional demands of the task with decreased target duration. This parametric deficit was found equally for both sensory targets. Accurate detection of visual and olfactory targets was associated specifically with increased LFP coherence, in the beta range, between the PFC and PPC, and with increased beta power in the PPC before the target's appearance in sham-lesioned rats. Readiness-associated changes in brain activity and visual and olfactory target detection were attenuated in the ACh-NBM-lesioned group. Accordingly, ACh may support supramodal attention via modulating activity in a frontoparietal cortical network, orchestrating a state of readiness to enhance target detection.

Key words: 192 IgG-saporin; acetylcholine; attention; frontoparietal; olfactory; visual

Significance Statement

We examined whether the neurochemical acetylcholine $(\mathrm{ACh})$ contributes to a state of readiness for target detection, by engaging frontoparietal cortical attentional networks independent of modality. We show that ACh supported alerting attention to an impending presentation of either visual or olfactory targets. Using local field potentials, enhanced stimulus detection was associated with an anticipatory increase in power in the beta oscillation range before the target's appearance within the posterior parietal cortex (PPC) as well as increased synchrony, also in beta, between the prefrontal cortex and PPC. These readinessassociated changes in brain activity and behavior were attenuated in rats with reduced cortical ACh. Thus, ACh may act, in a supramodal manner, to prepare frontoparietal cortical attentional networks for target detection.

\section{Introduction}

Converging evidence from human and animal studies indicate that the neurochemical acetylcholine $(\mathrm{ACh})$ plays an important

\footnotetext{
Received Aug. 19, 2017; revised Feb. 24, 2018; accepted March 13, 2018.

Author contributions: V.L., K.T.-N., and E.D.R. designed research; V.L. and L.-A.B. performed research; V.L., P.L., P.R.G., L.-A.B., K.T.-N., and E.D.R. analyzed data; V.L. and E.D.R. wrote the paper.

This work was supported by the Canadian Institute of Health Research Grant MOP102637 to E.D.R. and a National Science and Engineering Research Council Graduate Scholarship to V.L.

The authors declare no competing financial interests.

Correspondence should be addressed to either of the following: Dr. Vladimir Ljubojevic, University of Toronto

School of Medicine, Medical Sciences Building, 1 King's College Circle \#3172, Toronto, 0N M5S 1A8, Canada, E-mail:
}

role in attention (Stewart et al., 2001; Bentley et al., 2003; Botly and De Rosa, 2007, 2008; Furey et al., 2008). This role is largely mediated by ascending cholinergic fibers that originate in the nucleus basalis magnocellularis (NBM; Mesulam et al., 1983a,b) and project into frontoparietal cortical regions that serve as central nodes in a cortical attentional network (Posner and Petersen, 1990; Corbetta and Shulman, 2002). Models propose that fron-

vladimir.ljubojevic@mail.utoronto.ca; or Dr. Eve De Rosa, Cornell University, 173 Human Ecology Building, Ithaca, NY 14853, E-mail: eve.derosa@cornell.edu.

DOI:10.1523/JNEUROSCI.2350-17.2018

Copyright $\odot 2018$ the authors $\quad 0270-6474 / 18 / 383988-18 \$ 15.00 / 0$ 
toparietal cortical network supports attention by mobilizing the ACh input from the NBM into sensory cortices thus enhancing the processing within sensory cortices (Zaborszky, 2002; Disney and Aoki, 2008).

The five choice serial reaction time task (5-CSRTT) promotes sustained attention for the rat to monitor multiple spatial locations for briefly appearing targets (Robbins, 2002). Performance on the 5-CSRTT is associated with the release of ACh into the frontoparietal cortices (Passetti et al., 2000; McGaughy et al., 2002), and the integrity of cortical cholinergic projections is necessary for optimal 5-CSRTT performance (Lehmann et al., 2003; Dalley et al., 2004; Harati et al., 2008; Ljubojevic et al., 2014). Our previous work with a discrete trial 5-CSRTT suggested that ACh from the NBM modulates attention, in a supramodal fashion, aiding the detection of behaviorally relevant stimuli regardless of target stimulus modality (Ljubojevic et al., 2014). However, we relied solely on behavioral data and did not assess neuronal activity within a frontoparietal cortical network. Thus, in a separate cohort of rats, we recorded local field potentials (LFPs) in the prelimbic frontal cortex (PFC) and the posterior parietal cortex (PPC) during both visual and olfactory 5-CSRTT target detection.

These rats were tested on both modalities of target detection while we examined the neural mechanisms of attentional allocation by manipulating two behavioral parameters: (1) variability of the cue-target interval, to discriminate predictable versus variable deployment of attention; and (2) stimulus duration, to manipulate the attentional demands for target detection (McGaughy et al., 2002). Recording LFPs allowed us to assess frequency-dependent dynamic interactions within the PFC and PPC as well as the frequency-dependent synchrony, or coherence, between the PFC and PPC (von Stein and Sarnthein, 2000; Fries, 2005).

Cortical frequency-dependent synchrony between the frontal and parietal cortices may support attention by increasing readiness for processing of behaviorally relevant stimuli and enhancing the representation of attended stimuli (Fries et al., 2001; Salinas and Sejnowski, 2001; Fries, 2005; Buschman and Miller, 2007). Of particular relevance to our task, activity in the beta range has been correlated with long-range synchrony during multimodal integration (Roelfsema et al., 1997; von Stein et al., 1999; Kopell et al., 2000). Moreover, Antzoulatos and Miller (2016) have argued that beta oscillations within the parietal cortices and synchrony in beta between frontoparietal cortices may be important for filtering behaviorally relevant information, in an anticipatory way, when the primate was about to act on the presented stimulus. Thus we hypothesized that supramodal attention for accurate target detection would be supported by an increase power in beta range in the PPC as well as increased PFC-PPC beta synchrony, for predictable target presentation relative to variable and attentionally demanding target presentation.

A critical role of ACh may be to support frequency-dependent coherence in the frontoparietal cortical attentional network. If so, then disruption of NBM cholinergic afferents should suppress frontoparietal cortical dynamics and, as a result, impair target detection, whether olfactory or visual. In the present study, we also tested rats who received cholinergic lesions of the NBM, using the cholinergic immunotoxin 192 IgG-saporin (Wiley et al., 1991), to reduce cholinergic afferentation of the cortical mantle. We hypothesize that readiness-associated changes in brain activity and behavior would be attenuated in rats with reduced cortical ACh. These data would provide critical support for the role of the ascending cholinergic pathways to orchestrating a supramodal attentional capacity for target detection.

\section{Materials and Methods}

Apparatus. Four custom five-choice operant chambers $(25 \times 25 \times 25$ $\mathrm{cm}$; MED Associates), placed within sound-isolating and ventilated wooden boxes, were used for all behavioral testing (Ljubojevic et al., 2014).

Subjects. In the present study, we used a new cohort of 20 experimentally naive male Long-Evans rats (Charles River Laboratories) that weighed 200-225 g at the start of the experiment. The rats were individually housed in $45 \mathrm{~cm}$ long $\times 25 \mathrm{~cm}$ wide plastic tub cages and maintained on a reversed $12 \mathrm{~h}$ light/dark cycle (lights off at 8:00 A.M.) with behavioral testing occurring during the dark phase, typically between 9:00 A.M. and 4:00 P.M. Rats were maintained at 85\% of ad libitum free-feeding weight during the experiment. Rats were water-restricted to 25-30 min of daily ad libitum access and received water as a reward during testing. This study was approved by the University of Toronto's Institutional Animal Care Committee.

Behavioral training. A timeline of the experiment is shown in Figure 1. During the initial shaping and throughout testing, rats were trained to initiate a trial by breaking an infrared beam at the back of the chamber for $1 \mathrm{~s}$. This encouraged the rats to sit at the back of the chamber in anticipation of a target being presented. This trial initiation sequence was used throughout shaping and all testing conditions. Thus, this version of the 5-CSSRT had discrete trials. For a more detailed description of behavioral shaping and training procedures, see Ljubojevic et al. (2014).

Behavioral training on the 5-CSRTT started with the visual version of the task, so only light stimuli were presented. On each trial of the task, the rat had to respond to the brief light stimulus randomly presented in one of the five stimulus apertures. In addition to correct responses, we recorded four types of errors: (1) incorrect commission responses when the rat nose-poked in the wrong stimulus port, (2) omission errors when the rat failed to respond within the allocated time period, (3) premature responses when the rat responded before the stimulus presentation, and (4) perseverative responses when the rat responded to multiple locations within the same trial.

The first stage of the 5-CSRTT training had the following parameters: a target duration (TD) of $5 \mathrm{~s}$, an interstimulus interval (ISI; a time period between trial initiation and stimulus presentation) of $3 \mathrm{~s}$ and a limited hold ( $\mathrm{LH})$ period of $5 \mathrm{~s}$. To proceed to the next stage of training, the rat had to achieve a behavioral criterion of having 18 of 20 correct trials at any point during the session as well as the percentage of correct responses of $\geq 70 \%$ and omission rate of $\leq 20 \%$. The subsequent stages of behavioral training had a progressively shorter TD and progressively longer ISI, but the behavioral criterion stayed the same for each stage of training. Rats were considered to have completed the training for the visual version of the task when they met the behavioral criterion during a session with the following trial parameters: TD $=1 \mathrm{~s}$, ISI $=3 \mathrm{~s}$, and LH $=2 \mathrm{~s}$ (baseline conditions).

Following the successful acquisition of the visual 5-CSRTT, the rats were trained on the olfactory version of the 5-CSRTT. The first training stage involved coupled presentation of both visual and odor stimuli under baseline conditions and proceeded for 25 sessions. After that, odor stimuli were presented alone and the rats continued the training until they met the behavioral criterion on the olfactory task under the baseline conditions of TD $=1 \mathrm{~s}$, ITI $=3 \mathrm{~s}$, and $\mathrm{LH}=2 \mathrm{~s}$. The training stage with only odor stimuli presented was completed after 20 training sessions.

Following the successful acquisition of visual and olfactory tasks, rats were assigned into either a sham-lesion $(n=9)$ or ACh-NBM-lesion $(n=11)$ surgical group for reduced cholinergic cortical afferentation (Ljubojevic et al., 2014). The groups were matched on presurgical performance using the percentage of correct responses per session on visual and olfactory task performance.

Surgery. Surgeries were performed under aseptic conditions using isoflurane anesthesia ( $3 \%$ isoflurane with $1 \mathrm{~L} / \mathrm{min}$ oxygen for induction; $\sim 2 \%$ isoflurane with $1 \mathrm{~L} / \mathrm{min}$ oxygen for maintenance of anesthesia). Immediately before the incision, rats received an intraperitoneal injection of atropine $(0.05 \mathrm{mg} / \mathrm{kg})$ to prevent fluid build-up in the lungs. The ACh-NBM-lesioned rats received an injection of $0.2 \mu \mathrm{l}$ of $0.3 \mu \mathrm{g} / \mu \mathrm{l} 192$ IgG-saporin (Advanced Targeting Systems, lot \#64-124) dissolved in 


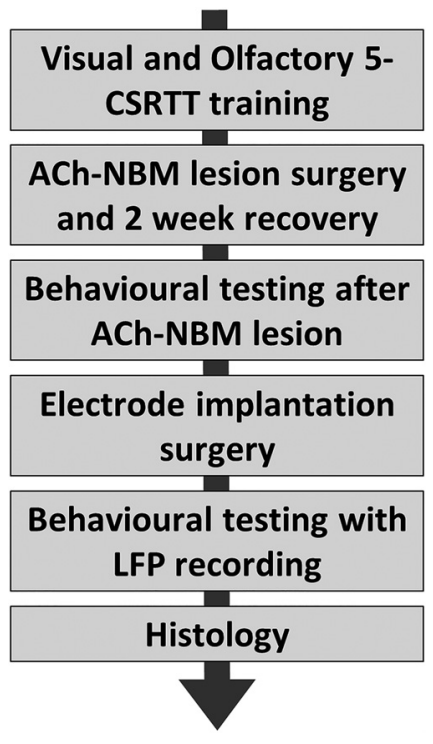

Figure 1. Timeline of the experiment.

sterile 0.1 м PBS, pH 7.4, per site. The sham-lesion group received an injection of $0.2 \mu \mathrm{l}$ of sterile $0.1 \mathrm{M}$ PBS, $\mathrm{pH}=7.4$, per injection site. The solutions were infused at a rate of $0.1 \mu \mathrm{l}$ per min, with an additional $3 \mathrm{~min}$ delay before the retraction of the injection. Both the anterior $(\mathrm{A} / \mathrm{P}-0.80$ $\mathrm{mm}, \mathrm{M} / \mathrm{L} \pm 2.6 \mathrm{~mm}, \mathrm{D} / \mathrm{V}-7.8 \mathrm{~mm}$, relative to bregma) and posterior (A/P $-1.32 \mathrm{~mm}, \mathrm{M} / \mathrm{L} \pm 3.0 \mathrm{~mm}, \mathrm{D} / \mathrm{V}-7.3 \mathrm{~mm}$, relative to bregma) NBM were targeted to maximize the extent of cholinergic deafferentation of the neocortex (Paxinos and Watson, 2007). The lesion coordinates and the immunotoxin dose were based on previous surgeries performed in our laboratory (Botly and De Rosa, 2009; Ljubojevic et al., 2014). After the injections were complete, we closed the incision with sterile silk sutures and then applied a topical analgesic ointment EMLA (2.5\% lidocaine and $2.5 \%$ prilocaine) around the sutures. Approximately $30 \mathrm{~min}$ before the end of the surgery, the rats were given a subcutaneous injection of an analgesic ketoprofen $(5 \mathrm{mg} / \mathrm{kg}$ ). Finally, the rats were given a subcutaneous injection of warm saline $(0.9 \% \mathrm{NaCl} ; 1 \mathrm{ml} / 100 \mathrm{~g}$ body weight, s.c.) immediately postsurgery to prevent dehydration.

Behavioral testing following the ACh-NBM lesion. Rats were given $14 \mathrm{~d}$ of postsurgical recovery with access to ad libitum water and food. They were water-restricted $24 \mathrm{~h}$ before the start of postsurgical testing. During all of the postsurgical data collection, the experimenters were blind to the surgical group of each rat. Each session was 60 trials long. The testing involved four types of sessions that were defined by the unique set of behavioral parameters, using TD, ISI, and a limited hold period of $2 \mathrm{~s}$ for all sessions. The TD, in Conditions 1, 2, and 3, parametrically manipulated the sensory data in such a way to increase the attentional demands for target detection and all of them had a fixed ISI of $3 \mathrm{~s}$. Condition 1 used $\mathrm{TD}=1.0 \mathrm{~s}$, which was the presurgical training TD; Condition 2 used $\mathrm{TD}=0.5 \mathrm{~s}$; and Condition 3 testing with $\mathrm{TD}=0.25 \mathrm{~s}$. The last testing condition, Condition 4 , used a TD $=1.0 \mathrm{~s}$ and variable ISIs of $1 \mathrm{~s}, 3 \mathrm{~s}$, and $5 \mathrm{~s}$, which were pseudorandomly distributed within a 60 trial session. Each condition type was used with both visual and olfactory version of the task for a total of eight postsurgical testing sessions. The rats did not receive retraining sessions postsurgery; rather, we first tested the rats under the conditions of low attentional load, gradually increasing the task difficulty as the postsurgical testing progressed. During these eight sessions, the rats were first tested under each condition for 2 consecutive d. In each $2 \mathrm{~d}$ block, the order was counterbalanced for target modality and surgical groups.

Electrode implantation surgery. The primary detector for LFP recordings was a Teflon-coated stainless steel wire (outer diameter $=0.0055$ inches; A-M Systems). Each recording site was implanted with a microelectrode assembly constituting of two mono-polar electrodes that were held together within a pair of hypodermic 29 guage stainless-steel guide cannulas that were themselves placed side-by-side in a small piece of heat shrink rubber. This setup placed the two electrodes tips $0.4 \mathrm{~mm}$ apart. For both implantation sites, the electrodes extended beyond the tip of the cannulas so that the wire was implanted into brain tissue, but the cannula was lowered only as far as the skull surface.

The surgeries were performed under aseptic conditions using isoflurane anesthesia ( $3 \%$ isoflurane with $1 \mathrm{~L} /$ min oxygen for induction; $2 \%$ isoflurane with $1 \mathrm{~L} / \mathrm{min}$ oxygen for maintenance of anesthesia). Following the incision, each rat was implanted with five skull screws that served to anchor the dental acrylic. Next a stainless steel screw electrode was implanted to the surface of the right cerebellum. The microelectrode assemblies were implanted in the right prelimbic cortex (PFC; A/P + 3.2 $\mathrm{mm}, \mathrm{M} / \mathrm{L} \pm 0.7 \mathrm{~mm}, \mathrm{D} / \mathrm{V}-3.4 \mathrm{~mm}$ from bregma) and right posterior parietal cortex (PPC; A/P $-4.5 \mathrm{~mm}, \mathrm{M} / \mathrm{L} \pm 2.2 \mathrm{~mm}$, and $\mathrm{D} / \mathrm{V}-1.3 \mathrm{~mm}$ from bregma) and fixed to the skull with dental acrylic. The recording and reference electrode wires were then connected to the head cap, and the cap itself was fixed to the skull with dental acrylic. Following the implantation of electrodes, a subcutaneous injection of ketoprofen (5 $\mathrm{mg} / \mathrm{kg}$ ) was delivered for analgesia and the incision was closed up to the head cap with silk sutures. Finally, a subcutaneous injection of warmed normal saline ( $1 \mathrm{ml} / 100 \mathrm{~g}$ body weight) was delivered immediately postsurgery to avoid dehydration.

Behavioral testing coupled with LFP recording. Following the electrode implantation surgery, the rats were given $48 \mathrm{~h}$ of recovery and were then habituated to the recording apparatus before the commencement of behavioral-LFP testing. LFPs were measured locally, as a voltage difference between two electrodes implanted in each brain area (prelimbic and posterior parietal cortex). The recording apparatus consisted of an 8 -channel headstage with $1000 \times$ gain and a commutator (NeuraLynx). The signal was then directed to the PowerLab data acquisition hardware and was finally recorded using LabChart software. The LFP signal was digitized at $4 \mathrm{kHz}$ and bandpass filtered at $0.5-200 \mathrm{~Hz}$. Custom made software written in Microsoft Visual Studio monitored the trial events of the behavioral testing session and then inserted the time stamps and corresponding comments to the LFP data. For each trial, comments were added that indicated different trial events (trial initiation with auditory cue, target appearance, response, reward delivery), and different types of responses (correct response, incorrect response, premature response, perseverative response, omission).

In this stage, rat behavior was tested while we simultaneously recorded the LFP signal from the PFC and PPC. The testing involved identical Conditions and order of Conditions to those used in the behavioral testing following the ACh-NBM lesion [Fixed (predictable) ISI with $\mathrm{TD}=1.0 \mathrm{~s}, \mathrm{TD}=0.5 \mathrm{~s}, \mathrm{TD}=0.25 \mathrm{~s}$, and then within-session variable (unpredictable) ISI with TD $=1.0 \mathrm{~s}$ ].

Following the conclusion of all behavioral testing, the rats were euthanized and their brains analyzed to determine the extent and specificity of the lesion and the location of the electrode placement (Ljubojevic et al., 2014).

Statistical analysis. Statistical analyses for histological and behavioral data were performed using the SPSS statistical software. We used significance level of $\alpha<0.05$ for all statistical analyses.

Results of the histological quantification were analyzed using twotailed independent samples $t$ tests surgical group (sham-lesioned, AChNBM-lesioned) as a between-groups factor. This analysis was performed for following outcome measures of the immunohistochemical data collection: number of choline acetyltransferase-immunoreactive (ChATIR) cells in the NBM number of ChAT-IR cells in the medial septum/ vertical limb nucleus of the diagonal band of Broca (MS/VDB), number of ChAT-IR cells in the horizontal limb nucleus of the diagonal band of Broca (HDB), and number of parvalbumin-immunoreactive cells in the NBM. Further, the same statistical method was used to compare two groups in the level of optical density from multiple cortical regions (prelimbic cortex, frontal area 3 , sensorimotor cortex, piriform cortex, hippocampus, posterior parietal cortex, visual cortex) following acetylcholine esterase (AChE) histochemical stain.

For each session, we calculated several measures of behavioral performance. We calculated the percentage of each response type (correct response, incorrect response, premature response, perseverative response, 
omission) per session by dividing the number of a particular response type by the total number of trials in a session (60 trials). We also calculated the measure of accuracy, which was defined as the number of correct responses divided by the total number of correct plus incorrect responses, expressed as a percentage (Bari et al., 2008). To analyze rats' performance, we used a mixed-design ANOVA with TD $(1.0,0.50,0.25 \mathrm{~s})$ as a within-subject factor and surgical group (sham-lesion and ACh-NBMlesion) as a between-subject factor. The analysis was conducted separately for visual and olfactory targets. Where significant effects were observed, principal analysis was followed-up by the independent-samples $t$ tests comparing the performance of two groups of rats separately at different TDs. To analyze the effect of the variable (unpredictable) ISI, we used a mixeddesign ANOVA with the ISI (fixed, variable) as a within-subject factor and surgical group (sham-lesioned, ACh-NBM-lesioned) as a betweengroups factor. All tests used $\alpha$ level of 0.05 .

The electrophysiological data were analyzed with custom made scripts written in MATLAB (MathWorks). We first isolated the signal that corresponded to target presentation. Epochs of interest started $2.0 \mathrm{~s}$ before the target presentation and ended $2.0 \mathrm{~s}$ after the target onset (epoch duration $=4 \mathrm{~s}$ ). We isolated epochs separately for each type of the response: correct response, incorrect response, and omission. Epochs were then visually inspected and trials where signal was contaminated with noise or movement artifacts were excluded from the analysis $(\sim 11.9 \%$ of trials). The LFP data analysis was conducted for both the PFC and the PPC sites.

The power spectral density in each epoch was calculated using fast Fourier transform. The LFP spectrum was calculated and shown in $0.25 \mathrm{~s}$ time bins. Baseline was defined as $0.5 \mathrm{~s}$ that occurred just before the trial onset. We normalized the data by dividing the observed power density in a frequency bin by the average power obtained from the same frequency bin during the baseline period. We obtained averaged normalized data separately for each response type in a session and used these data in the analysis. The plots show data that were first averaged across three sessions with a fixed ISI and then averaged across all rats belonging to an indicated surgical group. We also examined the PFC and PPC oscillatory patterns during the performance with the variable ISI. Because the session with variable ISI included trials with 1,3 , and 5 s ISI duration, we had to redefine the time window of interest so that we were measuring the same alerting signal across conditions.

We first examined normalized spectral power obtained from Correct and Incorrect trials for both groups on both types of tasks. Spectral power values were compared between the two surgical groups using a mixeddesign ANOVA with TD (1.0, 0.5, $0.25 \mathrm{~s})$, time bin (0.25 s time bins), frequency band (theta, beta, gamma), and response type (Correct response, Incorrect response) as within-subject factors and surgical group as a between-groups factor. This analysis was applied to standard frequency bands: theta $(4-10 \mathrm{~Hz})$; beta $(10-30 \mathrm{~Hz})$, and gamma $(30-80$ $\mathrm{Hz}$; Buzsáki and Draguhn, 2004). Delta frequency band (1.5-4 Hz) was not included in the analyses since the slow oscillatory pattern changes would not be detected using the $0.25 \mathrm{~s}$ time windows.

Then, to isolate LFP correlates of attentional processes associated with successful target detection, we calculated differential power values by subtracting the power obtained in Incorrect trials from those obtained on Correct trials. In that way, we made sure to subtract potential LFP changes that correlate with motor functions involved in the approach to and the response at the stimulus apertures. We did not focus on the trials that ended in omission, as in those trials the rat did not move toward and nosepoke into a stimulus aperture. We also did not focus on the premature responses as in those trials the target stimulus was not presented. Comparable analyses were conducted for the PFC and the PPC LFPs. Correct-Incorrect differential power values were compared between the two surgical groups using a mixed-design ANOVA with TD (1.0, 0.5, $0.25 \mathrm{~s}$ ), time bin ( $0.25 \mathrm{~s}$ time bins), and frequency band (theta, beta, gamma) as within-subject factors and surgical group as a betweengroups factor.

Next, we measured the coherence between PFC and PPC LFP signals to look for potential dynamic interactions between the two areas. The coherence, a measure of the correlation between two signals as a function of frequency, is the Fourier transform of the cross-covariance between two
Table 1. Number (mean \pm SEM) of ChAT- and parvalbumin-IR cells in basal forebrain subregions

\begin{tabular}{lllcc}
\hline & Control & Saporin & Reduction, $\%$ & $p$ \\
\hline ChAT & & & & \\
NBM & $355.89 \pm 9.45$ & $161.60 \pm 6.19$ & 54.6 & $<0.001^{*}$ \\
MS/VDB & $394.33 \pm 8.59$ & $379.10 \pm 9.01$ & 3.9 & 0.134 \\
$\quad$ HDB & $128.56 \pm 6.09$ & $127.60 \pm 5.80$ & 0.7 & 0.884 \\
Parvalbumin & & & & \\
$\quad$ NBM & $242.33 \pm 9.45$ & $223.10 \pm 6.82$ & 7.9 & 0.112 \\
\hline
\end{tabular}

Summary of the findings following the ChAT and parvalbumin immunostaining shows that there was a significant loss of cells in the NBM of ACh-NBM-lesioned rats compared to sham-lesioned rats. There were no group differences in the number of ChAT-immunoreactive cells in the MS/VDB and in the HDB, and no differences in the number of parvalbumin-immunoreactive cells in the NBM. *Indicates significant difference at $p<0.05$.

signals (Shumway and Stoffer, 2000; Ramalingam et al., 2013). It is calculated as the squared cross-spectrum between two signals divided by the product of the two auto spectra. The cross-spectra and auto-spectra were averaged over trials for a task condition before calculating the coherence. Coherence was calculated in each time bin at each frequency, which gave us a coherogram across the time-window of interest. Similar to the analysis of spectral power, the coherence was analyzed using mixed-design ANOVA with TD $(1.0,0.5,0.25 \mathrm{~s})$, time bin ( $0.25 \mathrm{~s}$ time bins), frequency band (theta, beta, gamma), and response type (Correct response, Incorrect response) as within-subject factors and surgical group as a betweengroups factor.

\section{Results}

\section{Immunohistological quantification}

The immunohistological quantification revealed that one AChNBM-lesioned rat did not have a sufficient decrement in the number of cholinergic cells in the NBM. Specifically, the reduction in the number of ChAT-IR cells in the NBM of this rat did not meet the criterion of more than 2 SD below the mean of the sham-lesioned group. The rat was removed from the behavioral analysis, leaving 10 rats in the ACh-NBM-lesioned group and 9 sham-lesioned rats.

\section{Cell counting}

We used two-tailed independent samples $t$ tests to compare the number of cells between ACh-NBM-lesioned rats and shamlesioned rats in different brain regions. The analysis revealed that ACh-NBM-lesioned rats had a significant decrease in the number of ChAT-IR cells in the NBM compared with shamlesioned rats $\left(t_{(17)}=17.54, p<0.001\right.$; Table 1$)$. The extent of the cholinergic cell loss in the NBM of ACh-NBM-lesioned rats was, on average, $54.59 \%(S D=5.49 \%)$. Importantly, the number of parvalbumin-immunoreactive cells in the NBM was equivalent between the two groups $\left(t_{(17)}=1.67\right.$, n.s. $)$, as well as the numbers of ChAT-IR cells in the MS/VDB $\left(t_{(17)}=1.57\right.$, n.s.) and in the HDB regions $\left(t_{(17)}=0.15\right.$, n.s.; Table 1$)$. Finally, we observed no signs of nonspecific tissue damage within the brain regions that were investigated. Sample photomicrographs of ChAT- and parvalbumin-stained sections of basal forebrain regions are shown in Figures 2 and 3.

\section{AChE densitometry}

Two-tailed independent samples $t$ tests were used to compare the adjusted optical density (OD) values (adjOD = raw OD value divided by striatal OD value) obtained from the AChE-stained slices from two surgical groups. The analysis revealed a significant reduction in neocortical AChE adjOD values in ACh-NBMlesioned rats compared with sham-lesioned rats. Moreover, there was no group difference in the adjOD values from the piriform cortex and the hippocampus. Table 2 provides mean adjOD values $( \pm$ SEM $)$ together with the results of the statistical analyses. 

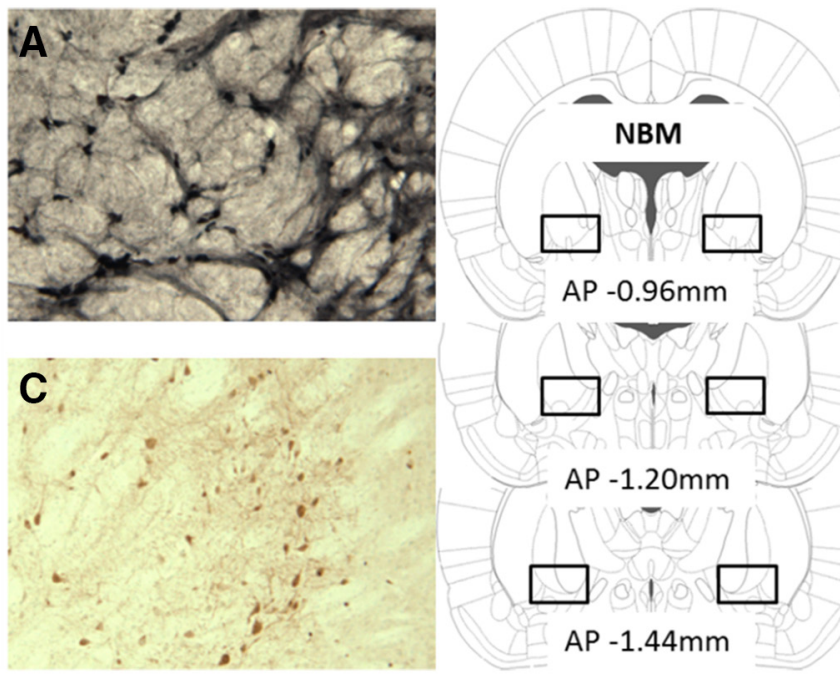
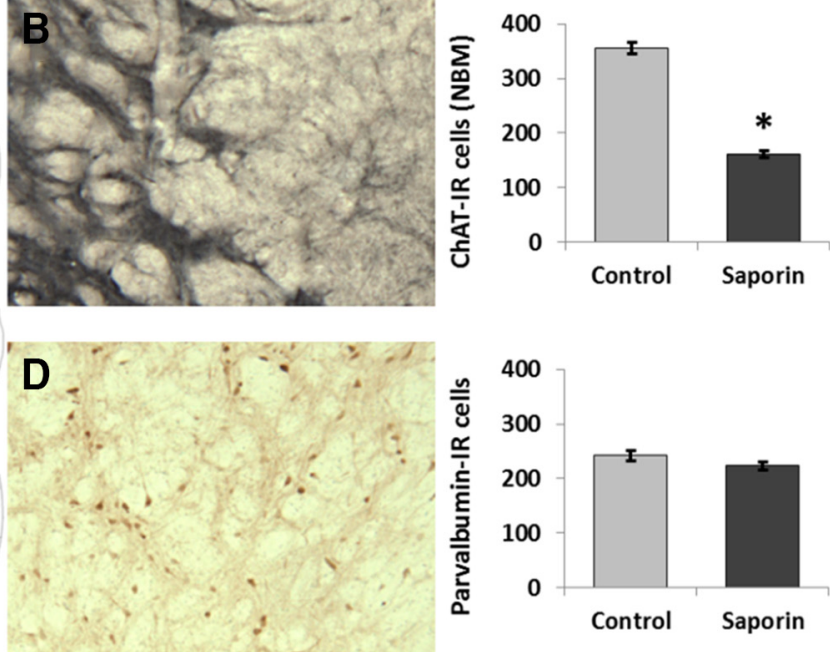

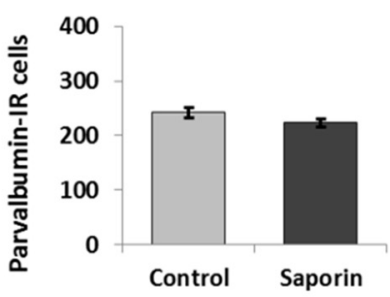

Figure 2. ChAT and parvalbumin immunohistochemistry of the nucleus basalis magnocellularis. The figure shows the photomicrographs of the ChAT- and parvalbumin-immunoreactive cells in the NBM of a ACh-NBM-lesioned $(\boldsymbol{B}, \boldsymbol{D})$ and sham-lesioned $(\boldsymbol{A}, \boldsymbol{C})$ rats. There was a marked decrease in the number of ChAT-IR cells in the NBM of the ACh-NBM-lesioned rats $(\boldsymbol{B})$ compared with sham-lesioned rats $(\boldsymbol{A})$. The number of parvalbumin-IR cells in the NBM was comparable between the groups $(\boldsymbol{C}, \boldsymbol{D})$. The rectangular outlines superimposed on the rat brain coronal schematics approximately correspond to the NBM cell-counting frames. Rat brain schematics were adapted from Paxinos and Watson (2007) and displayed coordinates refer to the AP plane. $\left(n_{\text {sham-lesioned }}=\right.$ $\left.9 ; n_{\text {ACh-NBM-lesioned }}=10\right)$. *Indicates significant difference at $p<0.05$. Bars show mean cell count \pm SEM.
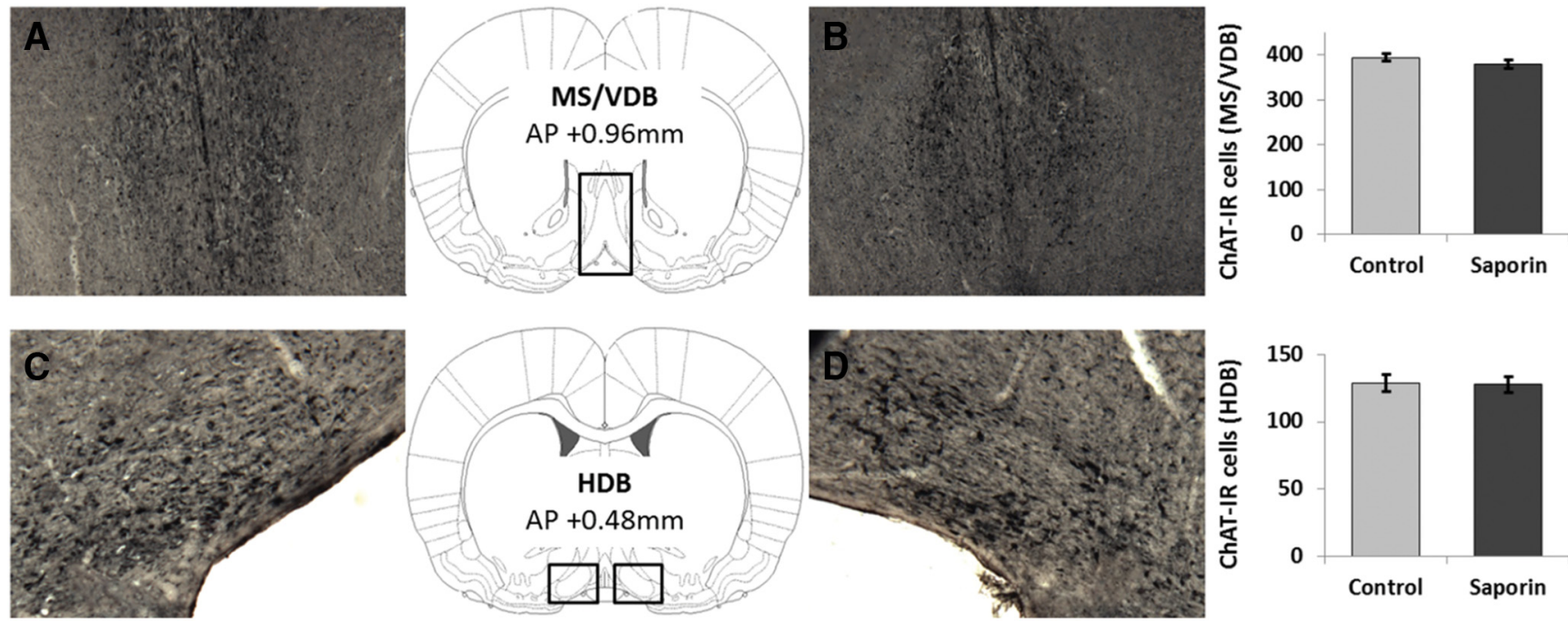

Figure 3. ChAT immunohistochemistry of the MS/NDB and the HDB. The figure depicts the rat MS/VDB $(\boldsymbol{A}, \boldsymbol{B})$ and $H D B(C, D)$ following the ChAT immunostaining. There was no group difference in the number of ChAT-IR cells in either of these areas. $\left(n_{\text {sham-lesioned }}=9 ; n_{\text {ACh-NBM-lesioned }}=10\right)$. Bars show mean cell count \pm SEM.

Table 2. Adjusted OD values (mean \pm SEM) from various cortical regions following AChE histochemistry

\begin{tabular}{lllcc}
\hline & Control & Saporin & Reduction, \% & $p$ \\
\hline & & & & \\
Fr3 (+2.76) & $0.70 \pm 0.01$ & $0.48 \pm 0.01$ & 30.6 & $<0.001^{*}$ \\
Prelimbic cortex (+2.76) & $0.70 \pm 0.01$ & $0.46 \pm 0.01$ & 33.9 & $<0.001^{*}$ \\
Motor/sensory (+1.32) & $0.65 \pm 0.01$ & $0.44 \pm 0.01$ & 32.0 & $<0.001^{*}$ \\
Piriform (+0.60) & $0.48 \pm 0.01$ & $0.46 \pm 0.01$ & 2.9 & 0.207 \\
Hippocampus (3.24) & $0.59 \pm 0.01$ & $0.59 \pm 0.01$ & -0.1 & 0.971 \\
Parietal (-3.96) & $0.61 \pm 0.01$ & $0.43 \pm 0.01$ & 29.1 & $<0.001^{*}$ \\
Visual (-4.80 to -5.16) & $0.53 \pm 0.01$ & $0.44 \pm 0.01$ & 17.9 & $<0.001^{*}$ \\
\hline
\end{tabular}

The effect of $192 \mathrm{lgG}$-saporin lesion on the adjusted $\mathrm{DD}$ values measured from various cortical regions following $\mathrm{AChE}$ staining, together with the results of statistical analysis. Anterior-posterior distance from bregma at which $0 D$ value was measured is shown in brackets. *Indicates significant difference at $p<0.05$.
Throughout the neocortical areas that were assessed, the loss of AChE-positive reaction products ranged from 17.9 to $33.9 \%$. Raw OD values from the striatum that were used for normalization did not differ between groups $\left(t_{(17)}=-0.51 ; \mathrm{M}_{\text {sham-lesioned }}=\right.$ 198.39, $\mathrm{SEM}_{\text {sham-lesioned }}=1.63 ; \mathrm{M}_{\mathrm{ACh}-\mathrm{NBM} \text {-lesion }}=199.59$, $\left.\mathrm{SEM}_{\mathrm{ACh} \text {-NBM-lesion }}=1.71\right)$. Sample photomicrographs of the coronal sections from the regions-of-interest with the AChE staining are shown in Figure 4.

\section{Behavioral testing following the ACh-NBM lesion}

All analyses (mixed-design ANOVA and follow-up tests) were performed using the $\alpha$ level of 0.05 . Greenhouse-Geisser correction was used in the analyses where the assumption of sphericity was violated. We observed a very low number of perseverative responses in both groups $(<0.5 \%$ per session) and therefore these data are not reported. 

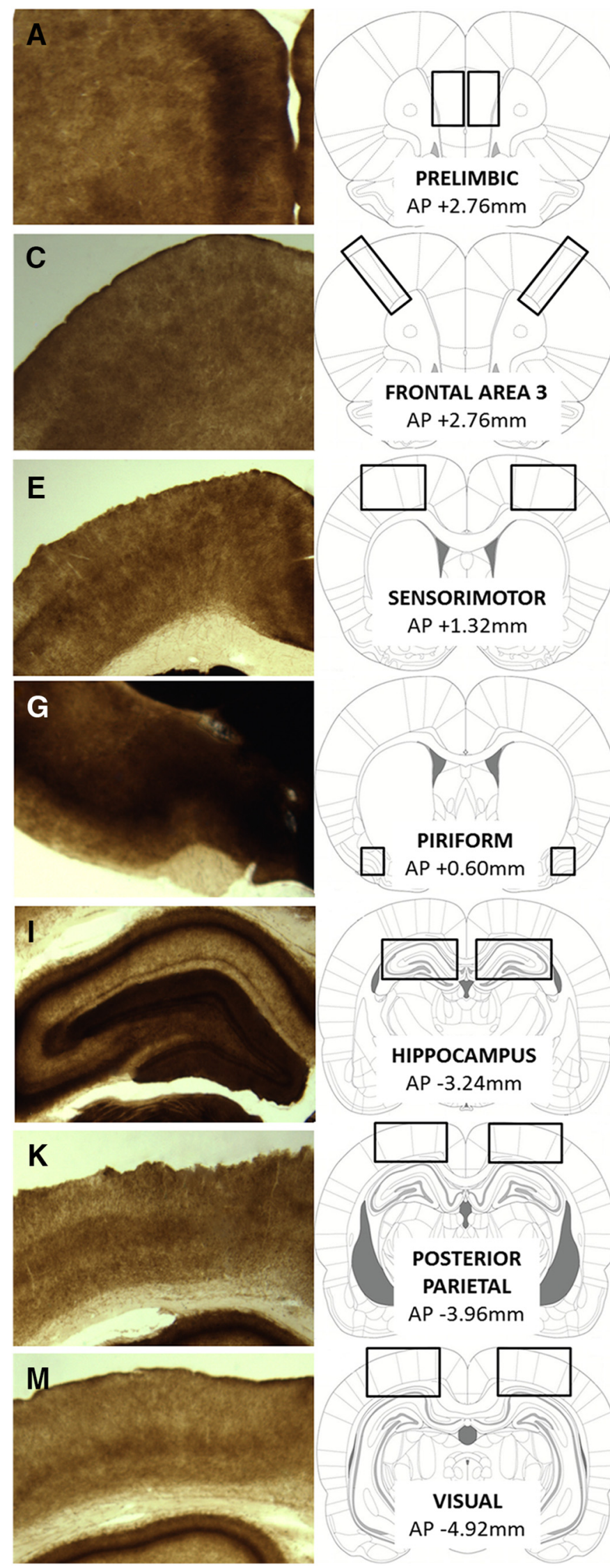

AP $-3.96 \mathrm{~mm}$

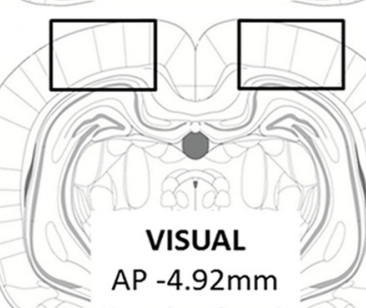

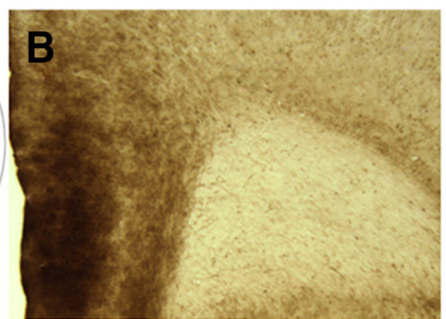
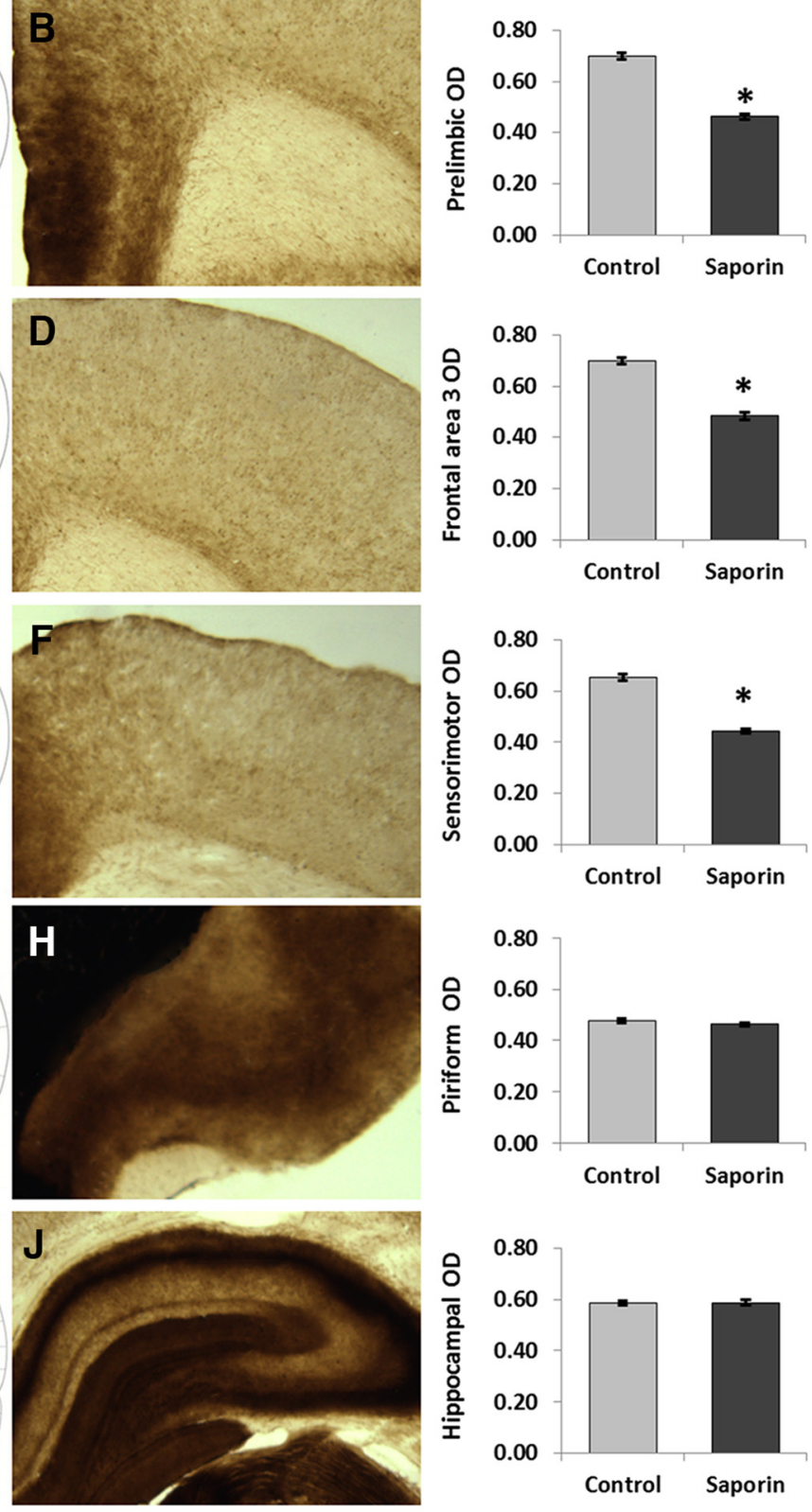
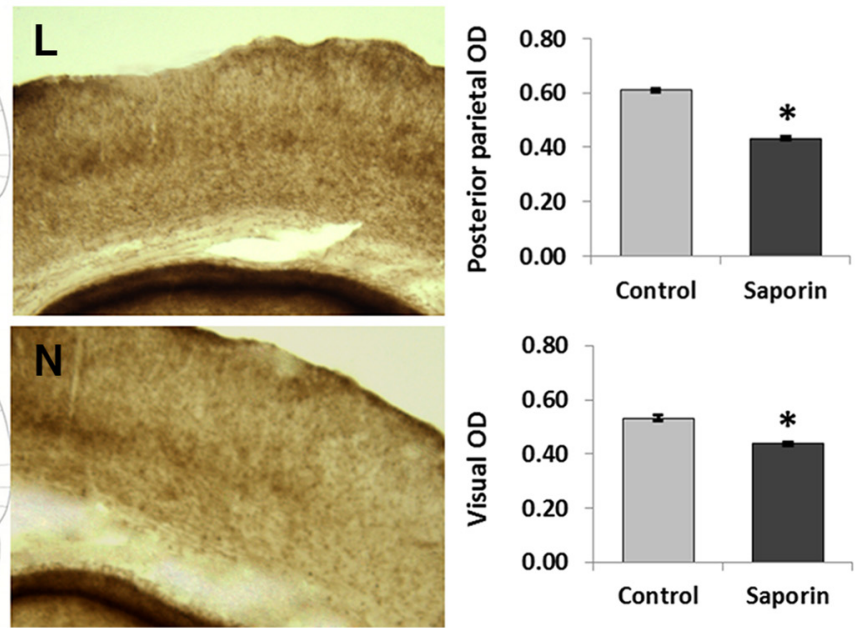

Figure 4. AChE histochemistry. The figure depicts various cortical areas following the AChE staining: prefrontal area $1(\boldsymbol{A}, \boldsymbol{B})$, prefrontal area $2(\boldsymbol{C}, \boldsymbol{D})$, prefrontal area $3(\boldsymbol{E}, \boldsymbol{F})$, olfactory cortex $(\boldsymbol{G}, \boldsymbol{H})$, hippocampus $(\boldsymbol{I}, \boldsymbol{J})$, posterior parietal cortex $(\boldsymbol{K}, \boldsymbol{L})$, and from the primary and secondary visual cortices $(\boldsymbol{M}, \boldsymbol{N}$; as delineated by Paxinos and Watson, 2007). We have observed significantly lower adjusted OD values in all neocortical areas of $A C h-N B M$-lesioned rats $(\boldsymbol{B}, \boldsymbol{D}, \boldsymbol{F}, \boldsymbol{L}, \boldsymbol{N})$. Importantly, the $0 D$ values from olfactory cortex and hippocampus were equivalent for two groups. $\left(n_{\text {sham-lesioned }}=9 ; n_{\text {ACh-NBM-lesioned }}=10\right)$. ${ }^{*}$ Indicates significant difference at $p<0.05$. Bars show mean $0 D \pm$ SEM. 


\begin{tabular}{|c|c|c|c|c|}
\hline Behavioral measure & $T D=1 s$ & $\mathrm{TD}=0.5 \mathrm{~s}$ & $\mathrm{TD}=0.25 \mathrm{~s}$ & Variable ITI \\
\hline \multicolumn{5}{|l|}{ Correct response, \% } \\
\hline Control & $77.78 \pm 1.98$ & $64.07 \pm 3.50$ & $49.07 \pm 4.15$ & $62.96 \pm 3.57$ \\
\hline Saporin & $77.17 \pm 3.63$ & $49.83 \pm 3.10^{*}$ & $31.50 \pm 3.20^{*}$ & $65.83 \pm 3.84$ \\
\hline \multicolumn{5}{|l|}{ Incorrect response, \% } \\
\hline Control & $6.30 \pm 0.91$ & $12.22 \pm 2.20$ & $22.59 \pm 2.77$ & $8.33 \pm 1.69$ \\
\hline Saporin & $7.17 \pm 1.41$ & $18.50 \pm 1.83^{*}$ & $18.67 \pm 1.81$ & $10.33 \pm 2.80$ \\
\hline \multicolumn{5}{|l|}{ Omission, \% } \\
\hline Control & $5.37 \pm 1.17$ & $14.63 \pm 2.00$ & $19.63 \pm 4.02$ & $13.52 \pm 1.65$ \\
\hline Saporin & $7.17 \pm 1.72$ & $25.00 \pm 3.51^{*}$ & $32.33 \pm 4.31^{*}$ & $11.50 \pm 1.48$ \\
\hline \multicolumn{5}{|c|}{ Premature response, $\%$} \\
\hline Control & $10.56 \pm 2.17$ & $9.07 \pm 1.69$ & $8.52 \pm 1.26$ & $15.00 \pm 2.94$ \\
\hline Saporin & $8.00 \pm 4.08$ & $6.50 \pm 1.39$ & $17.33 \pm 3.84$ & $12.33 \pm 1.80$ \\
\hline \multicolumn{5}{|l|}{ Correct latency, s } \\
\hline Control & $0.97 \pm 0.08$ & $0.76 \pm 0.02$ & $0.75 \pm 0.03$ & $0.94 \pm 0.07$ \\
\hline Saporin & $0.88 \pm 0.05$ & $0.78 \pm 0.03$ & $0.90 \pm 0.05$ & $0.95 \pm 0.05$ \\
\hline \multicolumn{5}{|l|}{ Reward latency, s } \\
\hline Control & $1.58 \pm 0.15$ & $1.45 \pm 0.04$ & $1.42 \pm 0.05$ & $1.44 \pm 0.06$ \\
\hline Saporin & $1.51 \pm 0.07$ & $2.11 \pm 0.59$ & $1.44 \pm 0.05$ & $1.48 \pm 0.07$ \\
\hline \multicolumn{5}{|l|}{ Accuracy, \% } \\
\hline Control & $92.76 \pm 1.37$ & $83.76 \pm 3.43$ & $68.18 \pm 2.77$ & $88.35 \pm 3.26$ \\
\hline Saporin & $91.46 \pm 1.37$ & $72.72 \pm 3.18^{*}$ & $62.37 \pm 3.52$ & $86.24 \pm 3.08$ \\
\hline
\end{tabular}

Summary of the rats' performance on a visual version of the 5-CSRTT across different testing conditions, following the cholinergic NBM lesion. Note the significant group differences in the percentage of correct responses and percentage of omissions per session under the conditions of increased attentional demand. *Reflects group difference at $p<0.05$.

\section{Effect of increasing the attentional demand}

To examine rats' performance on comparable visual and olfactory target detection tasks, we used a mixed-design ANOVA with $\mathrm{TD}(1.0,0.50,0.25 \mathrm{~s})$ as a within-subject factor and surgical group (sham-lesion and ACh-NBM-lesion) as a between-subject factor. The principal analysis, applied to the percentage of correct responses per session on the visual task, revealed significant effects of TD $\left(F_{(2,34)}=66.72, p<0.001\right)$, significant group difference $\left(F_{(1,17)}=13.95, p=0.002\right)$, and significant TD $\times$ group interaction $\left(F_{(2,34)}=3.88, p=0.030\right)$. Linear trend analysis revealed that both groups of rats were making fewer correct responses as the TD was decreasing ( sham-lesioned rats: $F_{(1,8)}=56.27, p<0.001$; ACh-NBM-lesioned rats: $\left.F_{(1,9)}=213.55, p<0.001\right)$. Next, we examined the percentage of correct responses on the olfactory task. Similar to what we observed on the visual version, the principal analysis revealed a significant effect of $\operatorname{TD}\left(F_{(2,34)}=62.82\right.$, $p<0.001)$, significant group difference $\left(F_{(1,17)}=12.96, p=\right.$ $0.002)$, and significant TD $\times$ group interaction $\left(F_{(2,34)}=5.16\right.$, $p=0.011)$. Again, linear trend analysis revealed that both groups of rats had fewer correct responses with the decreasing TD (sham-lesioned rats: $F_{(1,8)}=43.84, p<0.001$; ACh-NBMlesioned rats: $\left.F_{(1,9)}=86.05, p<0.001\right)$.

\section{Effect of the ACh-NBM-lesion}

Principal analyses looking at the percentage of correct responses per session revealed significant group $\times$ TD interactions on both visual and olfactory tasks. To examine the effects of the cholinergic NBM lesion in more detail, we followed-up the principal analysis by looking at the simple effects of the group factor at different levels of the TD factor. We did not observe any group difference in the number of correct responses under baseline conditions $(\mathrm{TD}=1 \mathrm{~s})$ on either version of the task (visual: $t_{(17)}=$ 0.14 , n.s.; olfactory: $t_{(17)}=0.98$, n.s.), which reflects presurgical training. Summary of the behavioral results from the visual and olfactory 5-CSRTT are summarized in Tables 3 and 4, respectively. Group differences emerged as we increased attentional
Table 4. Behavioral measures (mean + SEM) of the olfactory 5-CSRTT following the cholinergic NBM lesion

\begin{tabular}{lllll}
\hline Behavioral measure & $\mathrm{TD}=1 \mathrm{~s}$ & $\mathrm{TD}=0.5 \mathrm{~s}$ & $\mathrm{TD}=0.25 \mathrm{~s}$ & Variable ITI \\
\hline $\begin{array}{l}\text { Correct response, \% } \\
\quad \text { Control }\end{array}$ & $73.33 \pm 2.08$ & $65.37 \pm 4.65$ & $51.11 \pm 3.07$ & $60.74 \pm 3.45$ \\
$\quad$ Saporin & $70.33 \pm 2.22$ & $47.83 \pm 3.64^{*}$ & $33.17 \pm 3.58^{*}$ & $66.00 \pm 3.23$ \\
$\begin{array}{l}\text { Incorrect response, \% } \\
\quad \text { Control }\end{array}$ & $10.74 \pm 2.08$ & $8.89 \pm 1.47$ & $13.33 \pm 1.57$ & $11.30 \pm 1.96$ \\
$\quad$ Saporin & $9.33 \pm 1.74$ & $10.00 \pm 1.96$ & $19.17 \pm 1.15^{*}$ & $9.67 \pm 1.77$ \\
Omission, \% & & & & \\
$\quad$ Control & $7.59 \pm 2.68$ & $13.33 \pm 4.38$ & $23.52 \pm 2.58$ & $12.04 \pm 2.45$ \\
$\quad$ Saporin & $8.67 \pm 1.57$ & $31.00 \pm 5.24^{*}$ & $34.83 \pm 3.20^{*}$ & $9.17 \pm 1.71$ \\
$\begin{array}{l}\text { Premature response, \% } \\
\quad\end{array}$ & & & \\
$\quad$ Control & $8.33 \pm 1.39$ & $12.41 \pm 2.39$ & $11.85 \pm 1.85$ & $15.74 \pm 2.08$ \\
$\quad$ Saporin & $11.67 \pm 1.69$ & $11.17 \pm 2.68$ & $12.50 \pm 2.48$ & $14.83 \pm 3.02$ \\
Correct latency, s & & & & \\
$\quad$ Control & $1.05 \pm 0.04$ & $0.98 \pm 0.07$ & $0.75 \pm 0.05$ & $1.20 \pm 0.08$ \\
$\quad$ Saporin & $1.04 \pm 0.06$ & $0.86 \pm 0.07$ & $0.89 \pm 0.06$ & $1.12 \pm 0.07$ \\
Reward latency, s & & & & \\
$\quad$ Control & $1.40 \pm 0.04$ & $1.44 \pm 0.05$ & $1.36 \pm 0.05$ & $1.47 \pm 0.07$ \\
$\quad$ Saporin & $1.49 \pm 0.06$ & $1.47 \pm 0.05$ & $1.35 \pm 0.05$ & $1.44 \pm 0.07$ \\
Accuracy, \% & & & & \\
$\quad$ Control & $87.56 \pm 2.25$ & $87.63 \pm 2.29$ & $79.27 \pm 3.59$ & $84.05 \pm 1.99$ \\
$\quad$ Saporin & $88.27 \pm 2.20$ & $82.81 \pm 2.99$ & $62.31 \pm 3.67^{*}$ & $87.27 \pm 2.95$ \\
\hline
\end{tabular}

Summary of the rats' performance on an olfactory version of the 5-CSRTT across different testing conditions, following the cholinergic NBM lesion. Note the significant group differences in the percentage of correct responses and percentage of omissions per session under the conditions of increased attentional demand. *Reflects group difference at $p<0.05$.

demands of the task (Fig. 5). Testing with lower TD, decreasing the sensory data available, on the visual task revealed a significant decrease in the percentage of correct responses in ACh-NBMlesioned rats compared with sham-lesioned rats $(\mathrm{TD}=0.50 \mathrm{~s}$ : $t_{(17)}=3.06, p=0.007$; $\mathrm{TD}=0.25 \mathrm{~s}: t_{(17)}=3.39, p=0.003$; Figure $5 A)$. Decrease in correct responding at short TDs was accompanied by the increased number of omissions that ACh-NBMlesioned rats were making $\left(\mathrm{TD}=0.50 \mathrm{~s}: t_{(17)}=-2.49, p=0.023\right.$; $\mathrm{TD}=0.25 \mathrm{~s}: t_{(17)}=-2.14, p=0.047$; Figure $\left.5 B\right)$. Additionally, at $\mathrm{TD}=0.50 \mathrm{~s}$ ACh-NBM-lesioned rats made more incorrect responses than sham-lesioned rats $\left(\mathrm{TD}=0.50 \mathrm{~s}: t_{(17)}=-2.21, p=\right.$ 0.041).

Rats' performance on the olfactory task (Fig. 6) followed a similar pattern to that on the visual task. The two groups performed comparably at TD $=1 \mathrm{~s}$, but the behavioral decrement was only observed in the ACh-NBM-lesioned rats under conditions of increased attentional demand (percentage of correct responses; $\mathrm{TD}=0.50 \mathrm{~s}: t_{(17)}=3.01, p=0.008 ; \mathrm{TD}=0.25 \mathrm{~s}: t_{(17)}=$ $3.76, p=0.002$ ). The behavioral decrement was primarily a consequence of the increased number of omissions that ACh-NBMlesioned rats were making $\left(\mathrm{TD}=0.50 \mathrm{~s}: t_{(17)}=-2.56, p=0.021\right.$; $\left.\mathrm{TD}=0.25 \mathrm{~s}: t_{(17)}=-2.71, p=0.015\right)$. However, the ACh-NBMlesioned rats also had an increased number of incorrect responses at $\mathrm{TD}=0.25 \mathrm{~s}\left(t_{(17)}=-3.04, p=0.007\right)$. Behavioral findings from both visual and olfactory 5-CSRTT were comparable to those we previously observed (Ljubojevic et al., 2014).

\section{Effect of manipulating target predictability}

At this stage of postsurgical testing we also examined the effects of a within-session variable ISI (TD $=1.0 \mathrm{~s}$ ) by comparing rats' performance in these sessions to the baseline performance (TD = $1.0 \mathrm{~s}$, ISI $=3.0 \mathrm{~s}$ ). To analyze the data, we used a mixed-design ANOVA with the ISI (fixed, variable) as a within-subject factor and surgical group (sham-lesioned, ACh-NBM-lesioned) as a between-groups factor. The analysis revealed that rats had fewer correct responses in sessions with variable ISI compared with the 

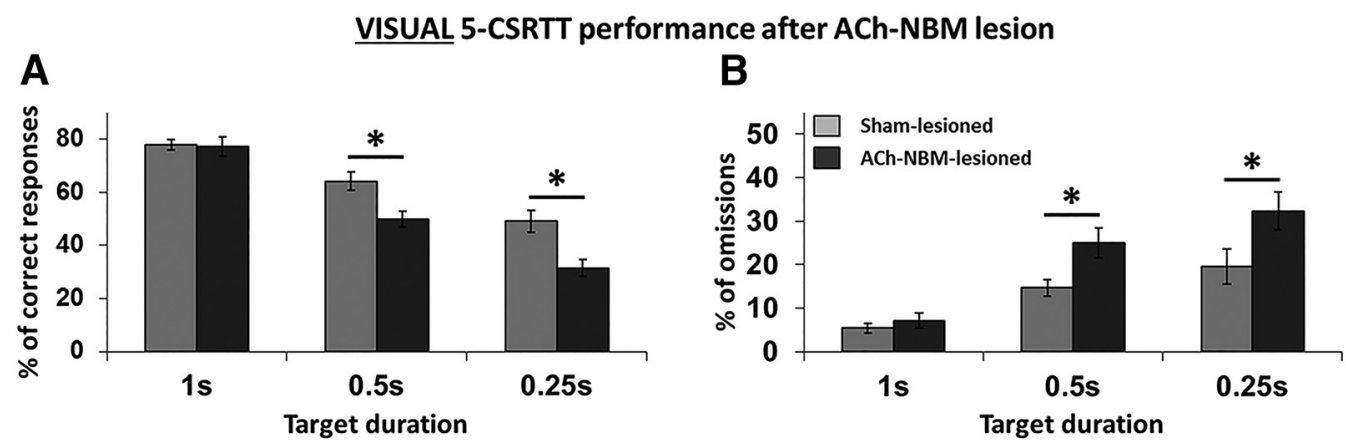

Figure 5. Visual target detection. The figure shows the effect of decreased TD on the percentage of correct responses $(\boldsymbol{A})$ and percentage of omissions $(\boldsymbol{B})$ for both surgical groups. Light gray: sham-lesioned $(n=9)$; dark gray: ACh-NBM-lesioned $(n=10)$. *Indicates significant difference at $p<0.05$. Bars show mean task performance \pm SEM. Results showing remaining behavioral measures of the task at this stage of testing are shown in Table 3.

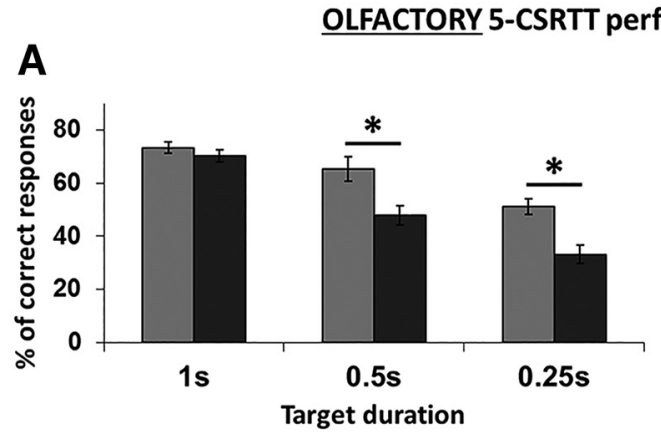

B

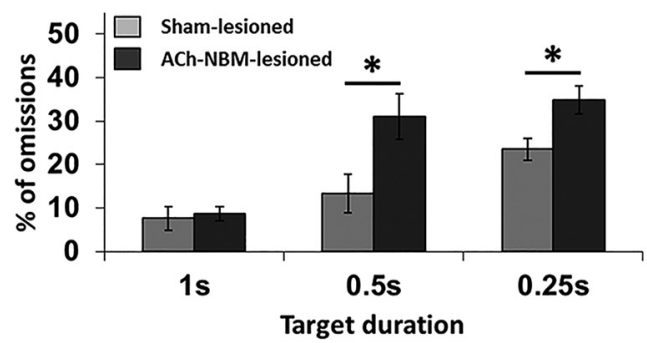

Figure 6. Olfactory target detection. The figure shows the effect of decreased TD on the percentage of correct responses $(\boldsymbol{A})$ and percentage of omissions (B) for both surgical groups. Light gray: sham-lesioned $(n=9)$; dark gray: ACh-NBM-lesioned $(n=10)$. ${ }^{*}$ Indicates significant difference at $p<0.05$. Bars show mean task performance \pm SEM. Results showing remaining behavioral measures of the task at this stage of testing are shown in Table 4.

fixed ISI on the visual version of the task $\left(F_{(1,17)}=13.59, p=\right.$ $0.002)$. This effect was not influenced by the cholinergic lesion (effect of group: $F_{(1,17)}<1$, n.s.; ISI $\times$ group interaction: $F_{(1,17)}<$ 1, n.s.). The decrease in the number of correct responses was accompanied by an increase in the number of omissions $\left(F_{(1,17)}=13.63\right.$, $p=0.002)$; manipulation of the ISI did not affect the number of incorrect $\left(F_{(1,17)}=3.24\right.$, n.s. $)$ and premature responses $\left(F_{(1,17)}=\right.$ 2.48 , n.s.).

In the olfactory version of the task, we also observed a decrease in the percentage of correct responses as a consequence of the variable ISI $\left(F_{(1,17)}=5.90, p=0.027\right)$. Again, this effect was not influenced by the cholinergic lesion (effect of group: $F_{(1,17)}<1$, n.s.; ISI $\times$ group interaction: $F_{(1,17)}=1.40$, n.s. $)$. Interestingly, on the olfactory task, variable ISI caused an increase in the number of premature responses $\left(F_{(1,17)}=8.73, p=0.009\right)$, but did not affect the number of incorrect responses $\left(F_{(1,17)}<1\right.$, n.s. $)$ or the number of omissions $\left(F_{(1,17)}=1.52\right.$, n.s. $)$.

\section{Behavioral testing coupled with LFP recording \\ LFP behavioral results}

In this stage of testing, we collected additional behavioral data over 8 testing sessions together with LFP data from the PFC and PPC. Two rats were excluded from the data analysis due to poor electrode placement, leaving $n=8$ rats in the sham-lesioned group and $n=9$ rats in the ACh-NBM-lesioned group. Despite the exclusion of two rats, the surgical groups still differed significantly in the number of cholinergic NBM cells $\left(t_{(15)}=17.81, p<\right.$ $0.001)$ and in the average neocortical adjOD $\left(t_{(15)}=16.35, p<\right.$ $0.001)$. A diagram depicting the location of electrode placement in all remaining rats is shown in Figure 7. Results of the behav- ioral testing on the visual task are shown in Table 5 and the results from the olfactory task are in Table 6.

A mixed-design ANOVA with TD (1.0, 0.5, $0.25 \mathrm{~s})$ as a withinsubject factor and surgical group (sham-lesion, ACh-NBMlesion) as a between-groups factor was used to analyze rats' performance. As was expected, behavioral findings in this stage of testing followed a similar pattern to what was observed during testing that followed cholinergic NBM lesion. We observed that the percentage of correct responses on the visual task was significantly affected by both of the factors (TD: $F_{(2,30)}=26.81, p<$ 0.001 ; group: $\left.F_{(1,15)}=36.15, p<0.001\right)$ as well as by the interaction between factors (group $\times$ TD: $F_{(2,30)}=4.85, p<0.015$ ). Follow-up analyses revealed that two groups performed comparably at $\mathrm{TD}=1.0 \mathrm{~s}\left(t_{(15)}=0.70\right.$, n.s. $)$, but ACh-NBM-lesioned group suffered a behavioral decrement at reduced TDs $(\mathrm{TD}=$ 0.50 s: $t_{(15)}=4.02, p=0.001 ; \mathrm{TD}=0.25 \mathrm{~s}: t_{(15)}=5.38, p<$ $0.001)$. This decrement was due to the ACh-NBM-lesioned rats making more omissions per session than sham-lesioned rats $\left(\mathrm{TD}=0.50 \mathrm{~s}: t_{(15)}=-2.76, p=0.015 ; \mathrm{TD}=0.25 \mathrm{~s}: t_{(15)}=\right.$ -3.77, $p=0.002$ ); numbers of incorrect and premature responses per session were not affected by the lesion.

The principal analysis examining the percentage of correct responses on the olfactory task revealed a significant effect of the TD factor $\left(F_{(1.59,23.83)}=80.35, p<0.001\right)$, a significant effect of group $\left(F_{(1,15)}=11.99, p=0.003\right)$, and a significant $\mathrm{TD} \times$ group interaction $\left(F_{(1.59,23.83)}=7.75, p=0.004\right)$. Follow-up analyses revealed that the ACh-NBM-lesioned rats maintained a normal level of correct responding under baseline conditions $\left(t_{(15)}=\right.$ 0.68 , n.s.), but suffered a behavioral decrement under the condi- 
tions of increased attentional demand $\left(\mathrm{TD}=0.50 \mathrm{~s}: t_{(15)}=3.74, p=0.002\right.$; $\left.\mathrm{TD}=0.25 \mathrm{~s}: t_{(15)}=6.02, p<0.001\right)$. At $\mathrm{TD}=0.50 \mathrm{~s}$ a group difference in the percentage of omissions per session trended toward significance $\left(t_{(15)}=-1.83, p=\right.$ 0.088 ), whereas at TD $=0.25 \mathrm{~s}$, the difference was statistically significant $\left(t_{(15)}=\right.$ $-3.81, p=0.002)$.

Next, we examined how rats' performance at $\mathrm{TD}=1.0 \mathrm{~s}$ was affected by the temporal predictability manipulation, using a mixed-design ANOVA with the ISI (fixed, variable) as a within-subject factor and surgical group (sham-lesioned, AChNBM-lesioned) as a between-groups factor. On both versions of the task, we observed a decrease in the percentage of correct responses as a consequence of variable ISI duration (visual: $F_{(1,15)}=$ 4.95, $p=0.042$; olfactory: $F_{(1,15)}=8.41$, $p=0.011)$. Two surgical groups were affected equally by this manipulation on both visual (group: $F_{(1,15)}<1$, n.s.; ISI $\times$ group interaction: $F_{(1,15)}<1$, n.s.) and olfactory (group: $F_{(1,15)}<1$, n.s.; ISI $\times$ group interaction: $F_{(1,15)}=1.73$, n.s.) versions of the task.

Power spectra changes accompanying visual 5-CSRTT performance

Spectral power values were compared between the two surgical groups using a mixed-design ANOVA with TD (1.0, 0.5, $0.25 \mathrm{~s})$, time bin ( $0.25 \mathrm{~s}$ time bins across $4 \mathrm{~s}$ time-interval of interest), frequency band (theta, beta, gamma), and response type (Correct response, Incorrect response) as within-subject factors and surgical group as a between-groups factor. The analysis did not reveal any significant effects of experimental variables on the spectral power within the PFC. On the other hand, when examining power spectra within the PPC, we observed significant frequency band $\times$ time bin $\times$ response type interaction $\left(F_{(30,450)}=2.11\right.$, $p=0.00069)$.

We then analyzed the PPC LFP data for effects of stimulus duration, time bin, response type, and surgical group variables for each frequency band separately. This follow-up analysis revealed no significant effects of any of the variables in the theta and gamma frequency bands. The same analysis of the PPC spectral power from beta frequency range revealed a significant time bin $\times$ response type $\times$ surgical group interaction $\left(F_{(15,225)}=2.21, p=0.0069\right)$, as well as the significant main effect of the time bin factor $\left(F_{(15,225)}=\right.$ $3.08, p=0.00015$ ).

From this point onward, we conducted two sets of analyses to further explain the observed time bin $\times$ response type $\times$ surgical group interaction. First, we examined whether the PPC beta power differs between Correct and Incorrect trials in shamlesioned rats and then separately in ACh-NBM-lesioned rats. Second, we examined how Correct-Incorrect differential power values differ between two surgical groups across different time bins.

For the analysis of the PPC beta oscillations in the shamlesioned rats we used a three-way repeated-measures ANOVA with TD (1.0, 0.5, $0.25 \mathrm{~s})$, response type (correct, incorrect), and time bin ( $0.25 \mathrm{~s}$ bins across the $4 \mathrm{~s}$ time-window of interest) as within-subject factors. We observed a PPC beta power difference between trials that ended in Correct and those that ended in Incorrect responses. Specifically, on the visual task (Fig. $8 A$ ), we did not see a significant effect of TD $\left(F_{(2,14)}<1, p=0.41\right.$, n.s. $)$ or response type $\left(F_{(1,7)}=2.14, p=0.17\right.$, n.s. $)$. However, we did observe a significant effect of the time bin factor $\left(F_{(15,105)}=4.01\right.$, $p=0.000011)$, and a significant time bin $\times$ response type interaction $\left(F_{(15,105)}=4.59, p<0.00001\right)$. We then examined the effects of the response type factor at different time bins. The analysis revealed that correct responding was associated with increased PPC beta power compared with incorrect responding during the period from $-0.75 \mathrm{~s}$ until $+0.25 \mathrm{~s}$ surrounding the 


\begin{tabular}{|c|c|c|c|c|}
\hline Behavioral measure & $\mathrm{TD}=1 \mathrm{~s}$ & $\mathrm{TD}=0.5 \mathrm{~s}$ & $\mathrm{TD}=0.25 \mathrm{~s}$ & Variable ITI \\
\hline \multicolumn{5}{|l|}{ Correct response, $\%$} \\
\hline Control & $73.96 \pm 2.50$ & $65.00 \pm 3.93$ & $55.42 \pm 3.74$ & $65.63 \pm 3.60$ \\
\hline Saporin & $69.81 \pm 5.11$ & $39.63 \pm 4.81^{*}$ & $27.04 \pm 3.70^{*}$ & $63.95 \pm 1.51$ \\
\hline \multicolumn{5}{|l|}{ Incorrect response, \% } \\
\hline Control & $3.54 \pm 0.86$ & $8.75 \pm 1.80$ & $12.71 \pm 3.49$ & $5.21 \pm 1.46$ \\
\hline Saporin & $5.56 \pm 0.83$ & $11.85 \pm 1.87$ & $13.70 \pm 2.40$ & $6.48 \pm 1.19$ \\
\hline \multicolumn{5}{|l|}{ Omission, \% } \\
\hline Control & $20.42 \pm 2.55$ & $19.58 \pm 3.19$ & $16.67 \pm 2.36$ & $15.21 \pm 2.88$ \\
\hline Saporin & $21.85 \pm 4.96$ & $37.22 \pm 5.31^{*}$ & $41.11 \pm 5.73^{*}$ & $19.63 \pm 3.67$ \\
\hline \multicolumn{5}{|c|}{ Premature response, $\%$} \\
\hline Control & $1.67 \pm 0.55$ & $6.46 \pm 1.49$ & $15.21 \pm 2.68$ & $13.75 \pm 4.49$ \\
\hline Saporin & $2.41 \pm 0.40$ & $10.56 \pm 2.91$ & $18.15 \pm 5.09$ & $17.35 \pm 4.71$ \\
\hline \multicolumn{5}{|l|}{ Correct latency, s } \\
\hline Control & $1.06 \pm 0.04$ & $0.99 \pm 0.04$ & $0.99 \pm 0.06$ & $1.10 \pm 0.07$ \\
\hline Saporin & $1.12 \pm 0.04$ & $1.06 \pm 0.08$ & $1.04 \pm 0.07$ & $1.09 \pm 0.07$ \\
\hline \multicolumn{5}{|l|}{ Reward latency, s } \\
\hline Control & $1.52 \pm 0.05$ & $1.64 \pm 0.09$ & $1.51 \pm 0.07$ & $1.57 \pm 0.10$ \\
\hline Saporin & $1.55 \pm 0.08$ & $1.47 \pm 0.05$ & $1.52 \pm 0.08$ & $1.44 \pm 0.08$ \\
\hline \multicolumn{5}{|l|}{ Accuracy, \% } \\
\hline Control & $95.45 \pm 1.59$ & $87.68 \pm 4.16$ & $81.55 \pm 4.01$ & $92.52 \pm 1.26$ \\
\hline Saporin & $92.28 \pm 1.12$ & $75.14 \pm 4.86$ & $65.20 \pm 6.91$ & $90.97 \pm 1.94$ \\
\hline
\end{tabular}

Summary of the rats' performance on a visual version of the 5-CSRTT across different testing conditions, obtained during LFP data collection. Note the significant group differences in the percentage of correct responses and percentage of omissions per session under the conditions of increased attentional demand. *Reflects group difference at $p<0.05$.

\begin{tabular}{|c|c|c|c|c|}
\hline Behavioral measure & $\mathrm{TD}=1 \mathrm{~s}$ & $\mathrm{TD}=0.5 \mathrm{~s}$ & $\mathrm{TD}=0.25 \mathrm{~s}$ & Variable ITI \\
\hline \multicolumn{5}{|l|}{ Correct response, \% } \\
\hline Control & $73.13 \pm 4.89$ & $63.54 \pm 4.58$ & $50.63 \pm 2.99$ & $62.29 \pm 3.20$ \\
\hline Saporin & $68.52 \pm 4.75$ & $44.63 \pm 2.50^{*}$ & $26.85 \pm 2.61^{*}$ & $64.44 \pm 2.72$ \\
\hline \multicolumn{5}{|c|}{ Incorrect response, $\%$} \\
\hline Control & $4.58 \pm 1.36$ & $6.67 \pm 1.89$ & $11.25 \pm 2.35$ & $6.88 \pm 1.90$ \\
\hline Saporin & $9.07 \pm 1.62$ & $12.96 \pm 2.30$ & $10.19 \pm 2.11$ & $6.85 \pm 1.13$ \\
\hline \multicolumn{5}{|l|}{ Omission, \% } \\
\hline Control & $17.29 \pm 5.48$ & $17.71 \pm 3.48$ & $24.17 \pm 3.85$ & $17.29 \pm 4.00$ \\
\hline Saporin & $15.00 \pm 4.27$ & $27.78 \pm 4.18$ & $50.74 \pm 5.61^{*}$ & $17.04 \pm 2.57$ \\
\hline \multicolumn{5}{|c|}{ Premature response, $\%$} \\
\hline Control & $4.38 \pm 2.02$ & $12.08 \pm 3.03$ & $13.96 \pm 2.52$ & $13.54 \pm 3.89$ \\
\hline Saporin & $7.04 \pm 1.61$ & $14.63 \pm 2.45$ & $12.22 \pm 2.66$ & $11.67 \pm 2.08$ \\
\hline \multicolumn{5}{|l|}{ Correct latency, s } \\
\hline Control & $1.07 \pm 0.07$ & $1.08 \pm 0.07$ & $0.88 \pm 0.04$ & $1.07 \pm 0.05$ \\
\hline Saporin & $1.01 \pm 0.05$ & $1.05 \pm 0.09$ & $0.87 \pm 0.07$ & $0.95 \pm 0.07$ \\
\hline \multicolumn{5}{|l|}{ Reward latency, s } \\
\hline Control & $1.58 \pm 0.09$ & $1.57 \pm 0.07$ & $1.48 \pm 0.06$ & $1.50 \pm 0.08$ \\
\hline Saporin & $1.50 \pm 0.07$ & $1.43 \pm 0.06$ & $1.44 \pm 0.07$ & $1.53 \pm 0.06$ \\
\hline \multicolumn{5}{|l|}{ Accuracy, \% } \\
\hline Control & $93.99 \pm 2.57$ & $89.77 \pm 4.17$ & $82.00 \pm 3.22$ & $90.07 \pm 2.27$ \\
\hline Saporin & $87.77 \pm 2.16$ & $78.21 \pm 3.01$ & $73.17 \pm 2.94$ & $90.38 \pm 1.87$ \\
\hline
\end{tabular}

Summary of the rats' performance on an olfactory version of the 5-CSRTT across different testing conditions, obtained during LFP data collection. Note the significant group differences in the percentage of correct responses and percentage of omissions per session under the conditions of increased attentional demand. *Reflects group difference at $p<0.05$.

target appearance (simple effects of response type factor: Time bin 6: $F_{(1,7)}=11.49, p=0.012$; Time bin $7: F_{(1,7)}=56.01, p=$ 0.00014; Time bin 8: $F_{(1,7)}=47.91, p=0.00023$; Time bin 9: $\left.F_{(1,7)}=28.94, p=0.0010\right)$. The remaining time bins had comparable beta power between the two response types. We then examined whether the individual differences in the degree of PPC beta power in the relevant peri-target period $(-0.75$ to $+0.25 \mathrm{~s}$ time interval around the target appearance) correlate with the individual differences in error rate. To do this, we obtained relevant session beta power value by first obtaining average power values across four time bins of interest $(-0.75$ to $+0.25 \mathrm{~s}$, peri-target) for all Correct and Incorrect trials in a session, and then averaging those peri-target power values across all Correct and Incorrect trials to obtain one power value representative of that particular session (compound session beta power). Then, we correlated compound session power with different measures of behavioral performance across sessions with different TDs, using Pearson's $r$ correlation, with two-tailed $\alpha=0.05$. We did not observe any significant correlations between compound power value and either percentage correct responses (target detection $=1.0 \mathrm{~s}: r_{(6)}=$ $0.57, p=0.14$, n.s.; target detection $=0.5 \mathrm{~s}: r_{(6)}=0.45, p=0.26$, n.s.; target detection $=0.25 \mathrm{~s}: r_{(6)}=0.43, p=0.28$, n.s.), percentage incorrect responses (target detection $=1.0 \mathrm{~s}: r_{(6)}=-0.41$, $p=0.31$, n.s.; target detection $=0.5 \mathrm{~s}: r_{(6)}=-0.48, p=0.23$, n.s.; target detection $=0.25 \mathrm{~s}: r_{(6)}=-0.46, p=0.25$, n.s.), or accuracy (target detection $=1.0 \mathrm{~s}: r_{(6)}=0.58, p=0.13$, n.s.; target detection $=0.5 \mathrm{~s}: r_{(6)}=0.49, p=0.22$, n.s.; target detection $=0.25 \mathrm{~s}$ : $r_{(6)}=0.46, p=0.25$, n.s.).

We then used the $3 \times 2 \times 16$ repeated-measures ANOVA with TD $\times$ response type $\times$ and time bin factors, to analyze the PPC beta oscillatory potentials in ACh-NBM-lesioned rats. The analysis did not reveal any significant effects of the three variables, nor did it reveal any significant interactions. Of interest, when examining simple effects of the response type variable, there was a slight increase in PPC beta power on Correct trials compared with Incorrect trials in Time bin 8 (0.25 s immediately before the target presentation), but this difference was not statistically significant $\left(F_{(1,8)}=3.76, p=0.088\right.$, n.s. $)$. Spectral power from ACh-NBM-lesioned rats is shown in Figure $8 B$.

Next, we examined the effects of experimental variables on the Correct-Incorrect PPC beta power differentials during visual 5-CSRTT. Spectrograms of the differential power values for both surgical groups are shown in Figure $8 C$. We used mixed-design ANOVA with TD $(1.0,0.5,0.25 \mathrm{~s})$ and time bin $(0.25 \mathrm{~s}$ bins across the $4 \mathrm{~s}$ time-window of interest) as within-subject factors and surgical group (sham-lesioned and ACh-NBM-lesioned) as a between-subject factor. We did not observe a significant effect of $\operatorname{TD}\left(F_{(2,30)}<1, p=0.45\right.$, n.s. $)$ or group $\left(F_{(1,15)}<1, p=0.33\right.$ n.s. $)$. However, we observed a significant effect of the time bin factor $\left(F_{(15,225)}=3.78, p<0.00001\right)$, and, importantly, a significant time bin $\times$ group interaction $\left(F_{(15,225)}=5.29, p<0.00001\right)$. To unpack the time bin $\times$ group interaction, we compared the beta power between the two surgical groups at each separate time bin (Fig. $8 D$ ). The analysis revealed that there was a significant group difference in Time bins 7-9 (simple effects of group factor: Time bin 7: $F_{(1,15)}=9.71, p=0.0071$; Time bin $8: F_{(1,15)}=14.69, p=$ 0.0016; Time bin 9: $\left.F_{(1,15)}=6.07, p=0.026\right)$.

Next, we examined the oscillatory patterns during the visual 5-CSRTT performance with the temporal predictability manipulation. Session with variable ISI included trials with 1,3 , and $5 \mathrm{~s}$ ISI duration, and therefore we redefined the time-window of interest. This analysis included the data from $1 \mathrm{~s}$ before the appearance of the target until $2 \mathrm{~s}$ after the target appearance. Testing sessions with within-session variable ISI duration all had TD of $1 \mathrm{~s}$ and therefore we compared these trials to the sessions with fixed ISI $=3 \mathrm{~s}$ and TD of $1 \mathrm{~s}$ (Condition 1 compared with Condition 4). We compared spectral power values between the two surgical groups using a mixed-design ANOVA with ISI condition (fixed ISI vs variable ISI), time bin ( $0.25 \mathrm{~s}$ time bins across $3 \mathrm{~s}$ time-interval of interest), frequency band (theta, beta, gamma), and response type (Correct response, Incorrect response) as within-subject factors and surgical group as a between-groups 


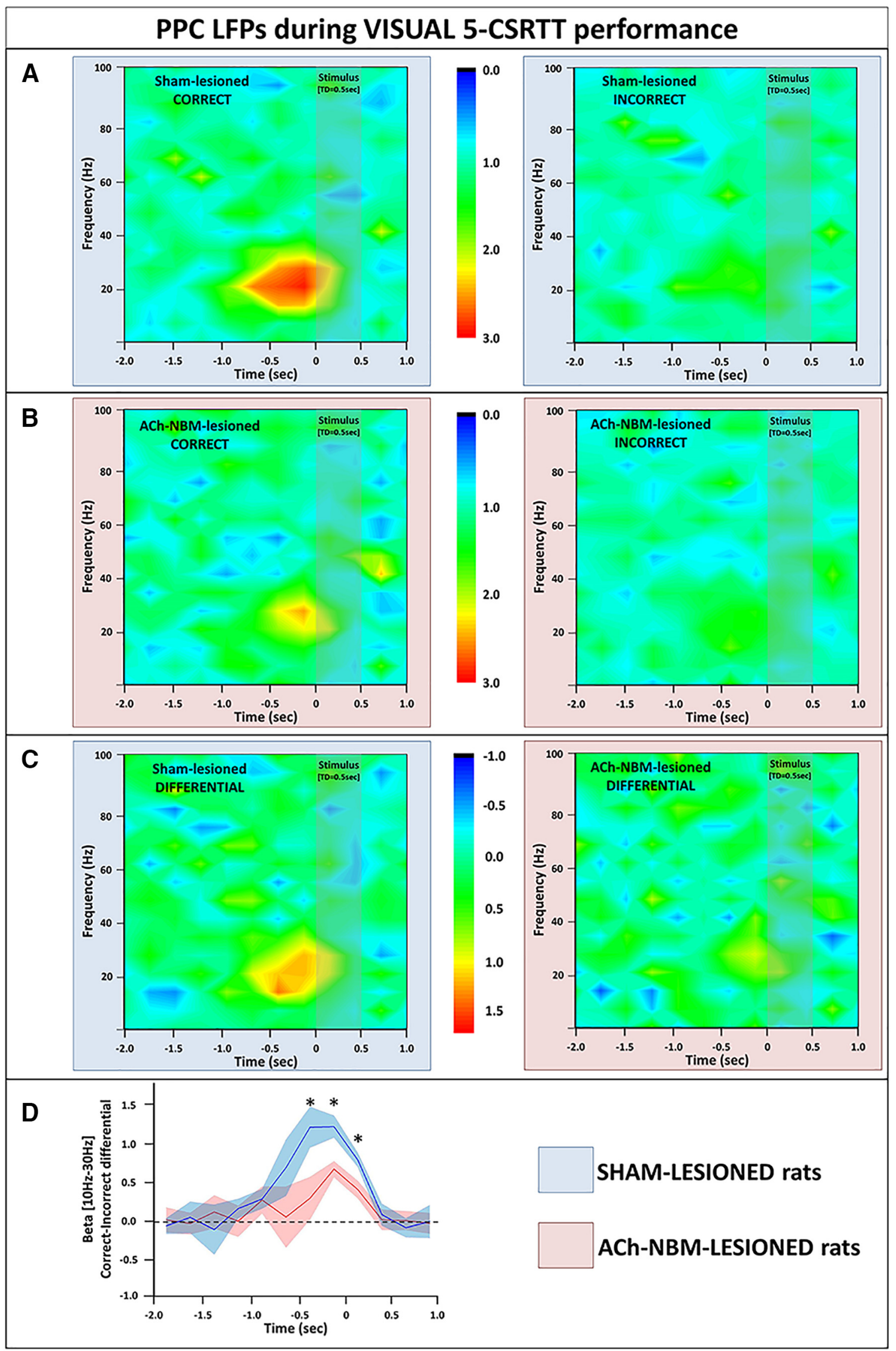

Figure 8. LFP findings from the PPC during performance on the visual target-detection task. $A$, We observed an increase in the PPC beta power (10-30 Hz) on correct trials (left), but not on incorrect trials (right) on the visual task. Spectrograms show power normalized against the power from the baseline period. $\boldsymbol{B}$, The normalized spectral power from the PPC of ACh-NBM-lesioned rats on correct (left) and incorrect trials (right) on the visual 5-CSRTT. Pretarget beta burst of power was attenuated in ACh-NBM-lesioned rats, compared with controls. (Figure legend continues.) 
factor. This analysis was conducted for LFP signals from both the PFC and the PPC, but we did not observe any significant effects of variables on either the PFC or the PPC spectral data. Given that previous analyses revealed significant changes in PPC beta power specifically in sham-lesioned rats immediately before target appearance, we felt motivated to further explore the effects of variables on oscillations in this frequency range. To do that, we used repeated-measures ANOVA with ISI condition (fixed ISI vs variable ISI), time bin ( $0.25 \mathrm{~s}$ time bins across $3 \mathrm{~s}$ time-interval of interest), and response type (Correct response, Incorrect response) as within-subject factors to analyze PPC beta power in sham-lesioned rats. Indeed, we observed a significant ISI condition $\times$ time bin $\times$ response type interaction $\left(F_{(11,77)}=2.94, p=\right.$ 0.0027). We then examined the ISI condition and time bin effects, separately for two response types, using repeated-measures ANOVA analyses. There were no significant effects of any of the variables on PPC beta power on incorrect trials. However, on Correct trials, we observed a significant effect of the time bin variable $\left(F_{(11,77)}=2.27\right.$, $p=0.019)$ and a significant time bin $\times$ ISI condition interaction $\left(F_{(11,77)}=3.89, p=0.00018\right)$. The analysis of the simple effects of the ISI condition variable across different time bins revealed that there is a significantly higher PPC beta power in fixed ISI condition compared with variable ISI condition in the period of $0.75 \mathrm{~s}$ immediately before target appearance (simple effects of ISI condition factor: Time bin 2: $F_{(1,7)}=5.90, p=0.045$; Time bin 3: $F_{(1,7)}=21.31, p=0.0024$; Time bin 4: $\left.F_{(1,7)}=16.77, p=0.0046\right)$. Finally, when we used repeated-measures ANOVA with ISI condition (fixed ISI vs variable ISI), time bin ( $0.25 \mathrm{~s}$ time bins across $3 \mathrm{~s}$ time-interval of interest), and response type (Correct response, Incorrect response) as withinsubject factors to analyze PPC beta power in ACh-NBM-lesioned rats, we did not observe significant effects of any of the variables, nor did we observe any significant factor interactions.

This pattern of findings suggests that Correct responding on the visual 5-CSRTT in sham-lesioned rats is associated with the increase in PPC beta power during the time period from -0.75 to $+0.25 \mathrm{~s}$ around the target appearance, compared with the comparable power spectra in trials that ended in incorrect response. This same PPC beta power increase is abolished in ACh-NBMlesioned rats. In fact, when we calculated Correct-Incorrect PPC beta power differential, and compared these values between two surgical groups, we observed attenuated Correct-Incorrect power differentials in ACh-NBM-lesioned rats compared with shamlesioned rats. Within the rest of the time-window of interest on the visual task, two groups had the equivalent power of beta oscillations in the PPC. Finally, the PPC beta power increase observed in sham-lesioned rats on Correct trials, is present only in sessions where there is temporal predictability of target appearance; this burst of PPC beta power is absent in sessions with within-session variable ISI.

\section{Power spectra changes accompanying olfactory 5-CSRTT performance}

The analysis of the PFC and PPC LFP data obtained during olfactory 5-CSRTT performance was conducted in similar manner to

\footnotetext{
$\leftarrow$

(Figure legend continued.) C, Spectrograms created by calculating the difference between the PPC power on correct trials and the PPC power on incorrect trials; left, shamlesioned; right, ACh-NBM-lesioned. D, Correct-Incorrect differential beta power was attenuated in ACh-NBM-lesioned rats compared with sham-lesioned rats. Shaded area around the lines shows SEM. Results showing the behavioral measures of the task at this stage of testing are shown in Table 5 . *Indicates significant difference at $p<0.05$.
}

that for the visual 5-CSRTT. In the primary analysis, the spectral power values were compared between the two surgical groups using a mixed-design ANOVA with TD (1.0, 0.5, $0.25 \mathrm{~s})$, time bin ( $0.25 \mathrm{~s}$ time bins across $4 \mathrm{~s}$ time-interval of interest), frequency band (theta, beta, gamma), and response type (Correct response, Incorrect response) as within-subject factors and surgical group as a between-groups factor. We did not observe any significant effects of experimental variables on the spectral power obtained from the PFC electrode site. On the other hand, we observed a significant frequency band $\times$ time bin $\times$ response type interaction $\left(F_{(30,450)}=1.97, p=0.0020\right)$ in the PPC.

We then analyzed the PPC LFP data for effects of stimulus duration, time bin, response type, and surgical group variables for each frequency band separately. Again, we observed no significant effects of any of the variables, nor any significant interactions when looking at the theta and gamma frequency bands. When we conducted the same $3 \times 16 \times 2 \times 2$ mixed-design ANOVA on the PPC spectral power from beta frequency range, we observed a significant time bin $\times$ response type $\times$ surgical group interaction $\left(F_{(15,225)}=1.84, p=0.031\right)$, as well as the significant main effect of the time bin factor $\left(F_{(15,225)}=3.08, p=\right.$ 0.00020).

As with the data from the visual 5-CSRTT, at this point we conducted two sets of analyses to further explain the observed time bin $\times$ response type $\times$ surgical group interaction. First, we examined the difference in PPC beta power between Correct and Incorrect trials separately in sham-lesioned rats and in $\mathrm{ACh}$ NBM-lesioned rats. Second, we calculated Correct-Incorrect differential power values and examined whether these values differ between two surgical groups.

For the analysis of the PPC beta oscillations in the shamlesioned rats on the olfactory task, we used a three-way repeatedmeasures ANOVA with TD (1.0, 0.5, $0.25 \mathrm{~s})$, response type (correct, incorrect), and time bin $(0.25 \mathrm{~s}$ bins across the $4 \mathrm{~s}$ timewindow of interest) as within-subject factors. The analysis revealed that there were no significant effects of TD $\left(F_{(2,14)}<1, p=\right.$ 0.47 , n.s. $)$ or response type $\left(F_{(1,7)}=1.92, p=0.21\right.$ n.s. $)$. Again, there was an effect of the time bin factor $\left(F_{(15,105)}=5.24, p<\right.$ $0.00001)$, and there was a significant time bin $\times$ response type interaction $\left(F_{(15,105)}=5.49, p<0.00001\right)$. A follow-up analysis revealed an increase in beta power in correct trials compared with incorrect trial during the period from $-0.75 \mathrm{~s}$ until $+0.50 \mathrm{~s}$ surrounding the target appearance (simple effects of response type factor: Time bin 6: $F_{(1,7)}=15.71, p=0.0054$; Time bin $7: F_{(1,7)}=$ 54.11, $p=0.00016$; Time bin 8: $F_{(1,7)}=51.45, p=0.00018$; Time bin 9: $F_{(1,7)}=30.11, p=0.00092$; Time bin 10: $F_{(1,7)}=10.04, p=$ $0.016)$. Remaining time bins had comparable beta power between the two response types. Power spectrum data from the olfactory 5-CSRTT are shown in Figure 9A. We then examined whether the individual differences in the degree of PPC beta power in the relevant peri-target period $(-0.75$ to $+0.50 \mathrm{~s}$ time interval around the target appearance) correlate with the individual differences in error rate, using the same method to that used in the visual 5-CSRTT analysis. This time, we observed significant correlation between compound session PPC beta power and the percentage correct responses in session with $\mathrm{TD}=1.0 \mathrm{~s}\left(r_{(6)}=\right.$ $0.74, p=0.034)$. However, we did not observe any other significant correlations. Namely, compound peri-stimulus PPC beta power did not correlate with the percentage correct responses at $\mathrm{TD}=0.5 \mathrm{~s}\left(r_{(6)}=0.41, p=0.31\right.$, n.s. $)$ or at $\mathrm{TD}=0.25 \mathrm{~s}\left(r_{(6)}=\right.$ $0.27, p=0.51$, n.s.). Further, peristimulus PPC beta power did not correlate with percentage incorrect responses (target detection $=1.0 \mathrm{~s}: r_{(6)}=-0.42, p=0.30$, n.s.; target detection $=0.5 \mathrm{~s}$ : 


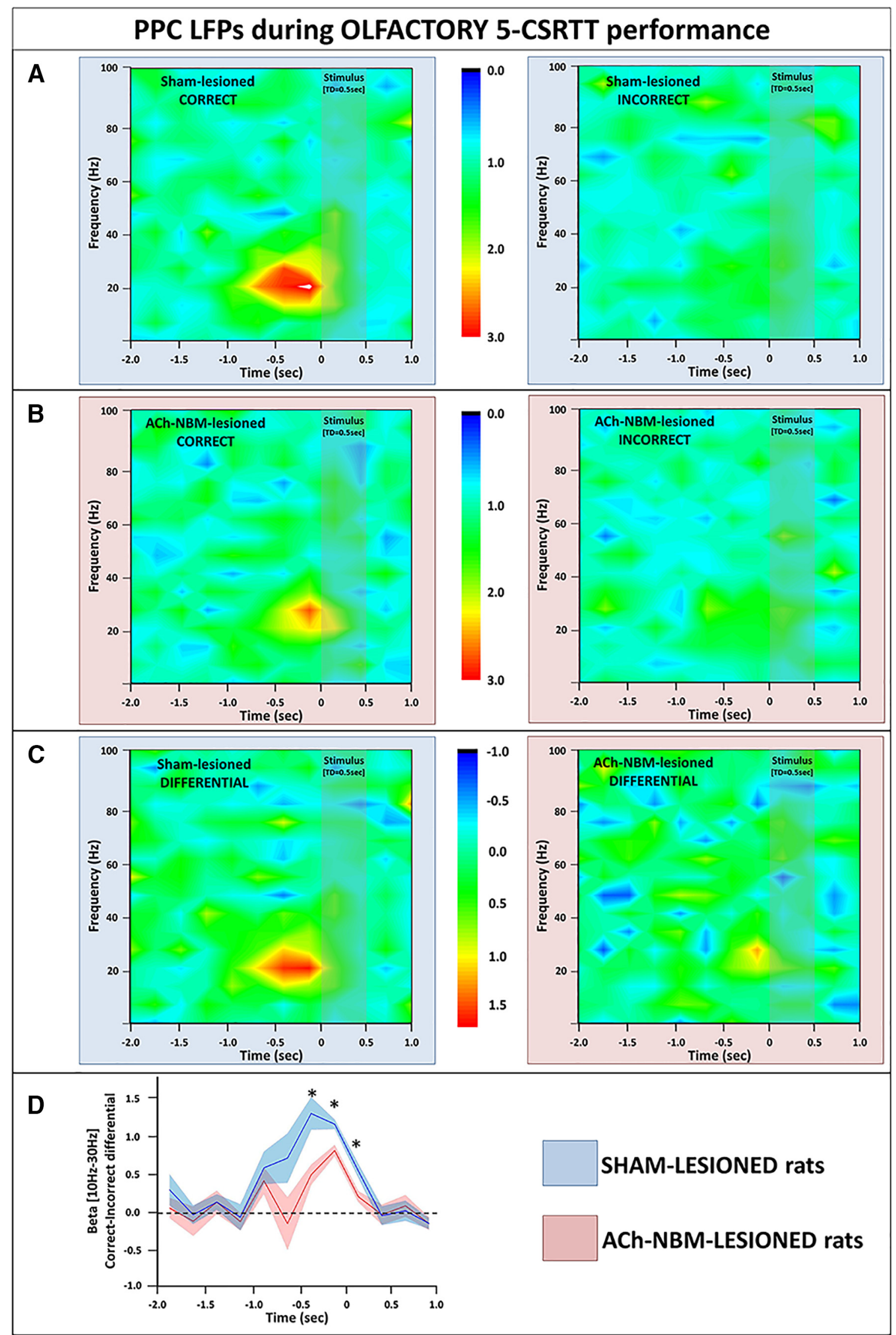

Figure 9. LFP findings from the PPC during the olfactory target-detection task. $A$, We observed an increase in the PPC beta power $(10-30 \mathrm{~Hz})$ on correct trials (left), but not on incorrect trials (right) on the olfactory task. Spectrograms show power normalized against the power from the baseline period. $\boldsymbol{B}$, The normalized spectral power from the PPC of ACh-NBM-lesioned rats on correct (left) and incorrect trials (right) on the olfactory 5-CSRTT. Pretarget beta burst of power was attenuated in ACh-NBM-lesioned rats compared with controls. (Figure legend continues.) 
$r_{(6)}=-0.29, p=0.49$, n.s.; target detection $=0.25 \mathrm{~s}: r_{(6)}=$ $-0.42, p=0.30$, n.s.), or with accuracy (target detection $=1.0 \mathrm{~s}$ : $r_{(6)}=0.57, p=0.14$, n.s.; target detection $=0.5 \mathrm{~s}: r_{(6)}=0.56, p=$ 0.15 , n.s.; target detection $=0.25 \mathrm{~s}: r_{(6)}=0.39, p=0.34$, n.s.) in any of the other sessions that we analyzed.

We then analyzed PPC beta oscillations in ACh-NBMlesioned rats using three-way repeated-measures ANOVA with $\mathrm{TD}(1.0,0.5,0.25 \mathrm{~s})$, response type (correct, incorrect), and time bin ( $0.25 \mathrm{~s}$ bins across the $4 \mathrm{~s}$ time-window of interest) as withinsubject factors. The analysis did not reveal any significant effects of the three variables, nor did it reveal any significant interactions, suggesting that the PPC beta power increase on correct trials is specific to sham-lesioned rats. Spectral power from AChNBM-lesioned rats is shown in Figure $9 B$.

Second follow-up to the primary analysis was the exploration of surgical group effects on PPC Correct-Incorrect differential beta power during olfactory 5-CSRTT performance (Fig. 9C). The pattern of oscillations we observed on the olfactory task was similar to what we reported for the visual one. We again used mixed-design ANOVA with TD (1.0, 0.5, $0.25 \mathrm{~s})$ and time bin ( $0.25 \mathrm{~s}$ bins across the $4 \mathrm{~s}$ time-window of interest) as withinsubject factors and surgical group (sham-lesioned and AChNBM-lesioned) as a between-subject factor. This analysis revealed that there was no significant effect of TD $\left(F_{(2,30)}<1, p=\right.$ 0.44 , n.s. $)$ or group $\left(F_{(1,15)}<1, p=0.41\right.$, n.s. $)$ factors. Again, we observed the significant effect of the time bin $\left(F_{(15,225)}=4.37\right.$, $p<0.00001)$ and a significant time bin $\times$ group interaction $\left(F_{(15,225)}=6.21, p<0.00001\right)$. Follow-up analyses revealed a decrease in differential beta power in ACh-NBM-lesioned group during the period from -0.50 to $+0.25 \mathrm{~s}$ around target appearance (simple effects of group factor: Time bin 7: $F_{(1,15)}=9.75$, $p=0.0070$; Time bin 8: $F_{(1,15)}=11.99, p=0.0035$; Time bin 9: $\left.F_{(1,15)}=7.62, p=0.015\right)$; results are illustrated in Figure $9 D$.

Next, we examined how PPC beta oscillatory pattern changes in sessions with temporally unpredictable target stimuli. This analysis was conducted for olfactory 5-CSRTT in the same manner as that for the visual 5-CSRTT. We compared spectral power values between the two surgical groups using a mixed-design ANOVA with ISI condition (fixed ISI vs variable ISI), time bin ( $0.25 \mathrm{~s}$ time bins across $3 \mathrm{~s}$ time-interval of interest), frequency band (theta, beta, gamma), and response type (Correct response, Incorrect response) as within-subject factors and surgical group as a between-groups factor. This analysis was conducted for LFP signals from both the PFC and the PPC. We did not observe any significant effects of variables on the PFC spectral data. We did not observe significant main effect of any of the variables on the PPC spectral data either, but we did observe significant five-way interaction $\left(F_{(22,330)}=1.75, p=0.021\right)$. We then analyzed the data separately for different frequencies using mixed-design ANOVA with ISI condition (fixed ISI vs variable ISI), time bin ( $0.25 \mathrm{~s}$ time bins across $3 \mathrm{~s}$ time-interval of interest), and response type (Correct response, Incorrect response) as within-subject factors and surgical group as a between-groups factor. There were no significant effects in theta and gamma range. In the beta range,

\section{$\leftarrow$}

(Figure legend continued.) C, The spectrograms created by calculating the difference between the PPC power on correct trials and the PPC power on incorrect trials; left, sham-lesioned; right, ACh-NBM-lesioned. D, Correct-Incorrect differential beta power was attenuated in ACh-NBM-lesioned rats compared with sham-lesioned rats. Shaded area around the lines shows SEM. Results showing the behavioral measures of the task at this stage of testing are shown in Table $6 .{ }^{*}$ Indicates significant difference at $p<0.05$. however, we observed significant ISI condition $X$ time bin $X$ response type $\times$ surgical group interaction $\left(F_{(11,165)}=2.21, p=\right.$ 0.016). To further unpack the interaction, we analyzed the data separately for 2 surgical groups using repeated-measures ANOVA with ISI condition (fixed ISI vs variable ISI), time bin ( $0.25 \mathrm{~s}$ time bins across $3 \mathrm{~s}$ time-interval of interest), and response type (Correct response, Incorrect response) as within-subject factors. In ACh-NBM-lesioned rats we did not observe any significant effects or significant interactions. In the analysis of the data from the sham-lesioned rats we observed significant effects of the time bin $\left(F_{(11,77)}=2.17, p=0.025\right)$ and the significant ISI condition $\times$ time bin $\times$ response type interaction $\left(F_{(11,77)}=\right.$ $3.18, p=0.0013)$. Finally, when analyzing the PPC LFP data from sham-lesioned rats, separately for Correct and Incorrect trials, we did not observe any significant effects of either ISI condition or time bin on the Incorrect trials, but we did observe significant findings on the Correct trials. Specifically, we saw an increase in PPC beta power in fixed ISI condition compared with variable ISI condition in Time bin $2\left(F_{(1,7)}=6.34, p=0.040\right)$, Time bin 3 $\left(F_{(1,7)}=32.45, p=0.00074\right)$, Time bin $4\left(F_{(1,7)}=28.79, p=\right.$ $0.0010)$, and Time bin $5\left(F_{(1,7)}=15.98, p=0.0052\right)$, corresponding to the period of -0.75 to $+0.25 \mathrm{~s}$ around the target stimulus onset.

The analysis of the LFP data obtained during olfactory 5-CSRTT performance provided largely comparable results as the analysis of the LFP data from the visual 5-CSRTT. In shamlesioned rats performing the olfactory 5-CSRTT we observed an increase in the PPC beta power on correct trials compared with the incorrect trials. This finding was not replicated in ACh-NBMlesioned rats. Analysis of the Correct-Incorrect differential beta power suggests that the cholinergic NBM-lesioned attenuated the pretarget beta burst that was observed in the sham-lesioned rats. Finally, the increase in beta power pretarget on correct trials is observed only in sessions where the presentation of the odor stimulus was predictable. The analysis showed that the beta burst disappears when the timing of the target appearance varies from trial to trial within one session.

\section{Effect of ACh-NBM-lesion on PFC-PPC coherence}

Finally, we examined whether the LFP coherence between the $\mathrm{PFC}$ and the PPC recording sites changed in relation to trial event or as a consequence of the cholinergic NBM lesion. The principal analysis involved a mixed-design ANOVA with TD $(1.0,0.5,0.25 \mathrm{~s})$ and time bin $(0.25 \mathrm{~s}$ bins across the $4 \mathrm{~s}$ timewindow of interest) as within-subject factors and surgical group (sham-lesioned and ACh-NBM-lesioned) as a betweensubject factor. The analysis was performed separately for the visual and the olfactory tasks, and the summary of the results is shown in Figure 10, $A$ and $B$, respectively. Figure 10 shows the average coherence specifically from the beta band as we did not observe any significant changes in PFC-PPC coherence in other frequency bands.

The principal analysis revealed an increased PFC-PPC coherence on both versions of the task, just before the target appearance that was attenuated in the ACh-NBM-lesioned group. On both versions of the task there was no effect of group (visual: $F_{(1,15)}<1, p=0.098$, n.s.; olfactory: $F_{(1,15)}<1, p=0.14$, n.s.) or TD factors (visual: $F_{(2,30)}<1, p=0.51$, n.s.; olfactory: $F_{(2,30)}<1$, $p=0.39$, n.s.), but we did observe a significant effect of time bin (visual: $F_{(15,225)}=3.24, p=0.00007$; olfactory: $F_{(15,225)}=2.97$, $p=0.00024)$ and a significant group $\times$ time bin interaction (visual: $F_{(15,225)}=3.99, p<0.00001$; olfactory: $F_{(15,225)}=3.48$, $p=0.000023)$. Follow-up analysis of the visual data revealed an 

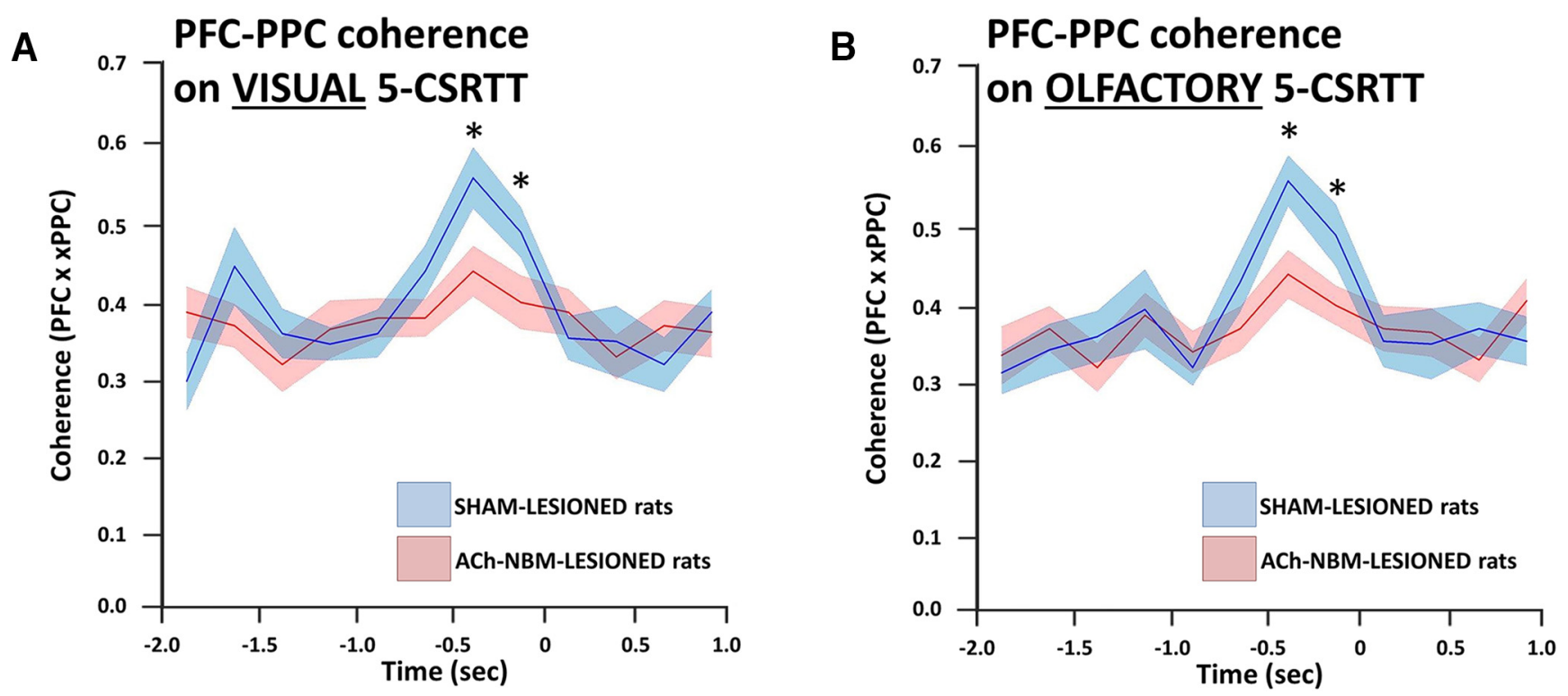

Figure 10. Changes in PFC-PPC beta coherence during target detection as a consequence of the ACh-NBM lesion. The average PFC-PPC beta (10-20 Hz) coherence was attenuated in ACh-NBM-lesioned rats during the prestimulus period on both visual $(\boldsymbol{A})$ and olfactory $(\boldsymbol{B})$ performance. Stimulus appears at time $=0 \mathrm{~s}$. ${ }^{*}$ Indicates significant difference at $p<0.05$. Shaded area around the lines shows SEM.

increase in PFC-PPC coherence that occurred from $-0.50 \mathrm{~s}$ until $0.0 \mathrm{~s}$ in sham-lesioned rats, but was attenuated in ACh-NBMlesioned rats (simple effects of group factor: Time bin $7: F_{(1,15)}=$ 9.38, $p=0.0079$; Time bin 8: $\left.F_{(1,15)}=6.74, p=0.020\right)$. A similar pattern was observed on the olfactory task. Namely, there was an increase in coherence during the same time window that was also attenuated after the cholinergic deafferentation of the neocortex (simple effects of group factor: Time bin $7: F_{(1,15)}=13.19, p=$ 0.0025; Time bin 8: $\left.F_{(1,15)}=6.07, p=0.022\right)$.

\section{Discussion}

In the current study, we observed that rats with reduced neocortical ACh had less correct responses than sham-lesioned rats on a visual and olfactory target detection task under the conditions of increased attentional demand. Our discrete trial 5-CSRTT allowed us to examine the predictable temporal deployment of attention in the fixed ISI condition (when to attend), while equating the duration of deployed attention across the fixed and variable ISI conditions (for how long to attend). These findings are consistent with multiple potential roles of ACh in attention, one of which is preparatory encoding for target detection (Himmelheber et al., 2000; Sarter et al., 2014).

The LFP data support this interpretation, revealing that optimal target detection, independent of modality, was related to anticipatory beta oscillations, as demonstrated by the increase in the power of PPC beta oscillations and the increase in PPC-PFC beta synchrony just before predictable target presentation. Further, these oscillatory changes were attenuated following cholinergic deafferentation of the neocortex. This was observed during behavioral testing following the cholinergic NBM-lesion surgery, and was replicated during behavioral testing that was coupled with LFP data collection.

ACh-NBM-lesioned rats had reduced correct responding absent of changes in sensorimotor capacities, motivation, and executive function (Robbins, 2002). They performed comparably to sham-lesioned rats under baseline conditions on both versions of the task, which suggested that their motivation and sensorimotor capacities were not affected by the lesion. Recent work (Yang et al., 2017) demonstrated with a visuospatial attention task that PPC activity reflected not only attentional resources for monitoring locations in space and target detection, but also sensorimotor engagement. Thus our findings may reflect cholinergic contributions to both attentional and sensorimotor processing.

ACh-NBM-lesioned rats did not exhibit impulsive and compulsive behavior, i.e., signs of disrupted executive function (Robbins, 2002), as indicated by the low number and comparable premature and perseverative responses, respectively. This discrete trial 5-CSRTT (Ljubojevic et al., 2014) limited the duration of the attentional deployment required for target detection; thus, we were able to measure temporal anticipatory attention (fixed ISI) in addition to the duration of attentional deployment (fixed and variable ISI). The observed preserved executive functioning in the ACh-NBM-lesioned rats may not be surprising because deficits in executive function on the 5-CSRTT have been shown to be primarily monoaminergic (Harrison et al., 1997; Higgins et al., 2003).

The present study confirm that cholinergic input into frontoparietal cortical attentional regions is necessary for processing of relevant environmental stimuli (Lehmann et al., 2003; Dalley et al., 2004; Harati et al., 2008), regardless of modality (Ljubojevic et al., 2014). Attentional functional neuroimaging studies with humans have revealed activation of frontoparietal cortical centers in response to stimuli from multiple modalities (Pardo et al., 1991; Cohen et al., 1992; Fink et al., 1997). Additionally, work with rodents has demonstrated that cholinergic modulation of the attentional network is necessary for performance on a variety of paradigms with multimodal or cross-modal components (Botly and De Rosa, 2007, 2008, 2009; Newman and McGaughy, 2008; Allison and Shoaib, 2013). This current study demonstrated that cholinergic modulation of the frontoparietal cortices is necessary specifically for the successful detection of visual and olfactory targets that are temporally predictable and spatially unpredictable. Once the targets were made temporally unpredictable, ACh- 
NBM-lesioned rats performed comparably to the controls on both versions of the task.

We also observed an increase in beta power in the PPC that was correlated with correct target detection on both versions of the task. Activity of the PPC has been associated with multiple cognitive processes (Corbetta et al., 2008; Bucci, 2009; Rawley and Constantinidis, 2009), including allocation of attention in space (Corbetta and Shulman, 2002; Bisley et al., 2011). For instance, damage to human PPC impairs visuospatial attentional shifts (Bays et al., 2010). Notably, changes in the PPC activity were observed in the healthy primate brain on multiple tasks that involve the disengagement of attention from irrelevant spatial locations and orienting of attention toward the location of relevant stimuli (Bisley and Goldberg, 2003; Thiel et al., 2004, 2005; Serences and Yantis, 2007). Work with rat models has demonstrated that single-unit activity in the PPC predicts the allocation of attention toward relevant visual stimuli (Broussard et al., 2006, 2009). Lesioned rats, in the current study, had significantly less PFC-PPC coherence and PPC beta power which suggests that cholinergic innervation of the frontoparietal cortical network is necessary for its optimal attentional functioning (Turchi and Sarter, 1997; Arnold et al., 2002; McGaughy et al., 2002; Sarter et al., 2005).

The group differences in frontoparietal cortical beta coherence and activation were observed in all sessions with the predictable target presentation. The anticipatory attention that may have facilitated predictable target detection for sham-lesioned rats was no longer useful in sessions with unpredictable target presentation. Accordingly, sham-lesioned rats lost their advantage over ACh-NBM-lesioned rats in sessions with variable ISI. We also observed beta synchrony between the PFC and the PPC, as well as the increased power of beta oscillations in the PPC during time periods that preceded the predictable appearance of targets, potentially priming sensory cortices for the impending appearance of a relevant stimulus. Changes in frontoparietal cortical activity that occur within the beta range have been previously observed during anticipatory periods on tasks involving stimulus detection (Herzog et al., 2014). More specifically, beta synchrony between the PFC and other neocortical sites was observed during a pretarget period in both rats (Totah et al., 2013) and primates (Liang et al., 2002) performing tasks of visual attention. Anticipatory attention, during the pretarget period, may have an overall facilitatory effect and could promote successful processing of the target stimulus once it appears (Frith and Dolan, 1997; Desimone, 1998; Duncan, 1998).

Although ACh has been shown to modulate other frequency bands than beta, e.g., PFC gamma and theta frequency bands with a cue detection task (Howe et al., 2017), beta oscillations have been observed in frontoparietal cortical regions (Liang et al., 2002; Totah et al., 2013; Herzog et al., 2014) and in higher sensorimotor integration centers (Baker, 2007; Donner et al., 2007; Fairhall et al., 2007) during attentional performance. Further, interactions between distal brain sites and their potential oscillatory synchronization commonly and favorably occurs within a beta frequency range (Kopell et al., 2000; Engel et al., 2001; Gross et al., 2004; Roopun et al., 2010). As such, beta rhythms can be used during attentional processing because it involves coordination of the processing capacities of multiple brain regions. Therefore, it may not be surprising that we have observed oscillatory changes in the PPC that were specific to the beta frequency band. These oscillatory changes likely reflected the coordinated 'activation' of a subpopulation of the
PPC that contributed to the overall functioning of the frontoparietal cortical network.

In conclusion, we have replicated that cholinergic innervation of a frontoparietal cortical attentional network is necessary for successful visual and olfactory target detection, suggesting a supramodal character of the frontoparietal attentional system. We have also shown that the task performance is accompanied by an increase in LFP beta coherence between the PFC and PPC and by an increase in the power of beta oscillations in the PPC. These changes in brain activity occurred during the period preceding the accurate and predictable detection of the target's appearance, and likely reflect on how learning modulates the temporal deployment of attention.

\section{References}

Allison C, Shoaib M (2013) Nicotine improves performance in an attentional set shifting task in rats. Neuropharmacology 64:314-320. CrossRef Medline

Antzoulatos EG, Miller EK (2016) Synchronous beta rhythms of frontoparietal networks support only behaviorally relevant representations. Elife 5: e17822. CrossRef Medline

Arnold HM, Burk JA, Hodgson EM, Sarter M, Bruno JP (2002) Differential cortical acetylcholine release in rats performing a sustained attention task versus behavioral control tasks that do not explicitly tax attention. Neuroscience 114:451-460. CrossRef Medline

Baker SN (2007) Oscillatory interactions between sensorimotor cortex and the periphery. Curr Opin Neurobiol 17:649-655. CrossRef Medline

Bari A, Dalley JW, Robbins TW (2008) The application of the 5-choice serial reaction time task for the assessment of visual attentional processes and impulse control in rats. Nat Protocols 3:759-767. CrossRef Medline

Bays PM, Singh-Curry V, Gorgoraptis N, Driver J, Husain M (2010) Integration of goal- and stimulus-related visual signals revealed by damage to human parietal cortex. J Neurosci 30:5968-5978. CrossRef Medline

Bentley P, Vuilleumier P, Thiel CM, Driver J, Dolan RJ (2003) Cholinergic enhancement modulates neural correlates of selective attention and emotional processing. Neuroimage 20:58-70. CrossRef Medline

Bisley JW, Goldberg ME (2003) Neuronal activity in the lateral intraparietal area and spatial attention. Science 299:81-86. CrossRef Medline

Bisley JW, Mirpour K, Arcizet F, Ong WS (2011) The role of the lateral intraparietal area in orienting attention and its implications for visual search. Eur J Neurosci 33:1982-1990. CrossRef Medline

Botly LC, De Rosa E (2007) Cholinergic influences on feature binding. Behav Neurosci 121:264-276. CrossRef Medline

Botly LC, De Rosa E (2008) A cross-species investigation of acetylcholine, attention, and feature binding. Psychol Sci 19:1185-1193. CrossRef Medline

Botly LC, De Rosa E (2009) Cholinergic deafferentation of the neocortex using 192 IgG-saporin impairs feature binding in rats. J Neurosci 29: 4120-4130. CrossRef Medline

Broussard JI, Karelina K, Sarter M, Givens B (2009) Cholinergic optimization of cue-evoked parietal activity during challenged attentional performance. Eur J Neurosci 29:1711-1722. CrossRef Medline

Broussard J, Sarter M, Givens B (2006) Neuronal correlates of signal detection in the posterior parietal cortex of rats performing a sustained attention task. Neuroscience 143:407-417. CrossRef Medline

Bucci DJ (2009) Posterior parietal cortex: an interface between attention and learning? Neurobiol Learn Mem 91:114-120. CrossRef Medline

Buschman TJ, Miller EK (2007) Top-down versus bottom-up control of attention in the prefrontal and posterior parietal cortices. Science 315: 1860-1862. CrossRef Medline

Buzsaki G, Draguhn A (2004) Neuronal oscillations in cortical networks. Science 304:1926-1929. CrossRef Medline

Cohen RM, Semple WE, Gross M, King AC, Nordahl TE (1992) Metabolic brain pattern of sustained auditory discrimination. Exp Brain Res 92:165172. Medline

Corbetta M, Shulman GL (2002) Control of goal-directed and stimulusdriven attention in the brain. Nat Rev Neurosci 3:201-215. CrossRef Medline 
Corbetta M, Patel G, Shulman GL (2008) The reorienting system of the human brain: from environment to theory of mind. Neuron 58:306-324. CrossRef Medline

Dalley JW, Theobald DE, Bouger P, Chudasama Y, Cardinal RN, Robbins TW (2004) Cortical cholinergic function and deficits in visual attentional performance in rats following $192 \mathrm{IgG}$-saporin-induced lesions of the medial prefrontal cortex. Cereb Cortex 14:922-932. CrossRef Medline

Desimone R (1998) Visual attention mediated by biased competition in extrastriate visual cortex. Philos Trans R Soc Lond B Biol Sci 353:1245-1255. CrossRef Medline

Disney AA, Aoki C (2008) Muscarinic acetylcholine receptors in macaque V1 are most frequently expressed by parvalbumin-immunoreactive neurons. J Comp Neurol 507:1748-1762. CrossRef Medline

Donner TH, Siegel M, Oostenveld R, Fries P, Bauer M, Engel AK (2007) Population activity in the human dorsal pathway predicts the accuracy of visual motion detection. J Neurophysiol 98:345-359. CrossRef Medline

Duncan J (1998) Converging levels of analysis in the cognitive neuroscience of visual attention. Philos Trans R Soc Lond B Biol Sci 353:1307-1317. CrossRef Medline

Engel AK, Fries P, Singer W (2001) Dynamic predictions: oscillations and synchrony in top-down processing. Nat Rev Neurosci 2:704-716. CrossRef Medline

Fairhall SL, Kirk IJ, Hamm JP (2007) Volition and the idle cortex: beta oscillatory activity preceding planned and spontaneous movement. Conscious Cogn 16:221-228. CrossRef Medline

Fink GR, Halligan PW, Marshall JC, Frith CD, Frackowiak RS, Dolan RJ (1997) Neural mechanisms involved in the processing of global and local aspects of hierarchically organized visual stimuli. Brain 120:1779-1791. CrossRef Medline

Fries P (2005) A mechanism for cognitive dynamics: neuronal communication through neuronal coherence. Trends Cogn Sci 9:474-480. CrossRef Medline

Fries P, Reynolds JH, Rorie AE, Desimone R (2001) Modulation of oscillatory neuronal synchronization by selective visual attention. Science 291: 1560-1563. CrossRef Medline

Frith C, Dolan RJ (1997) Brain mechanisms associated with top-down processes in perception. Philos Trans R Soc Lond B Biol Sci 352:1221-1230. CrossRef Medline

Furey ML, Pietrini P, Haxby JV, Drevets WC (2008) Selective effects of cholinergic modulation on task performance during selective attention. Neuropsychopharmacology 33:913-923. CrossRef Medline

Gross J, Schmitz F, Schnitzler I, Kessler K, Shapiro K, Hommel B, Schnitzler A (2004) Modulation of long-range neural synchrony reflects temporal limitations of visual attention in humans. Proc Natl Acad Sci U S A 101: 13050-13055. CrossRef Medline

Harati H, Barbelivien A, Cosquer B, Majchrzak M, Cassel JC (2008) Selective cholinergic lesions in the rat nucleus basalis magnocellularis with limited damage in the medial septum specifically alter attention performance in the five-choice serial reaction time task. Neuroscience 153:7283. CrossRef Medline

Harrison AA, Everitt BJ, Robbins TW (1997) Central 5-HT depletion enhances impulsive responding without affecting the accuracy of attentional performance: interactions with dopaminergic mechanisms. Psychopharmacology 133:329-342. CrossRef Medline

Herzog L, Salehi K, Bohon KS, Wiest MC (2014) Prestimulus frontalparietal coherence predicts auditory detection performance in rats. J Neurophysiol 111:1986-2000. CrossRef Medline

Higgins GA, Enderlin M, Haman M, Fletcher PJ (2003) The 5-HT2A receptor antagonist M100,907 attenuates motor and "impulsive-type" behaviours produced by NMDA receptor antagonism. Psychopharmacology 170:309-319. CrossRef Medline

Himmelheber AM, Sarter M, Bruno JP (2000) Increases in cortical acetylcholine release during sustained attention performance in rats. Brain Res Cogn Brain Res 9:313-325. CrossRef Medline

Howe WM, Gritton HJ, Lusk NA, Roberts EA, Hetrick VL, Berke JD, Sarter M (2017) Acetylcholine release in prefrontal cortex promotes gamma oscillations and theta-gamma coupling during cue detection. J Neurosci 37: 3215-3230. CrossRef Medline

Kopell N, Ermentrout GB, Whittington MA, Traub RD (2000) Gamma rhythms and beta rhythms have different synchronization properties. Proc Natl Acad Sci U S A 97:1867-1872. CrossRef Medline
Lehmann O, Grottick AJ, Cassel JC, Higgins GA (2003) A double dissociation between serial reaction time and radial maze performance in rats subjected to 192 IgG-saporin lesions of the nucleus basalis and/or the septal region. Eur J Neurosci 18:651-666. CrossRef Medline

Liang H, Bressler SL, Ding M, Truccolo WA, Nakamura R (2002) Synchronized activity in prefrontal cortex during anticipation of visuomotor processing. Neuroreport 13:2011-2015. CrossRef Medline

Ljubojevic V, Luu P, De Rosa E (2014) Cholinergic contributions to supramodal attentional processes in rats. J Neurosci 34:2264-2275. CrossRef Medline

McGaughy J, Dalley JW, Morrison CH, Everitt BJ, Robbins TW (2002) Selective behavioral and neurochemical effects of cholinergic lesions produced by intrabasalis infusions of $192 \mathrm{IgG}$-saporin on attentional performance in a five-choice serial reaction time task. J Neurosci 22: 1905-1913. Medline

Mesulam MM, Mufson EJ, Levey AI, Wainer BH （1983a） Cholinergic innervation of cortex by the basal forebrain: cytochemistry and cortical connections of the septal area, diagonal band nuclei, nucleus basalis (substantia innominata), and hypothalamus in the rhesus monkey. J Comp Neurol 214: 170-197. CrossRef Medline

Mesulam MM, Mufson EJ, Wainer BH, Levey AI (1983b) Central cholinergic pathways in the rat: an overview based on an alternative nomenclature (Ch1-Ch6). Neuroscience 10:1185-1201. CrossRef Medline

Newman LA, McGaughy J (2008) Cholinergic deafferentation of prefrontal cortex increases sensitivity to cross-modal distractors during a sustained attention task. J Neurosci 28:2642-2650. CrossRef Medline

Pardo JV, Fox PT, Raichle ME (1991) Localization of a human system for sustained attention by positron emission tomography. Nature 349:61-64. CrossRef Medline

Passetti F, Dalley JW, O'Connell MT, Everitt BJ, Robbins TW (2000) Increased acetylcholine release in the rat medial prefrontal cortex during performance of a visual attentional task. Eur J Neurosci 12:3051-3058. CrossRef Medline

Paxinos, G., and Watson, C (2007) The rat brain in stereotaxic coordinates. New York, NY: Aacademic.

Posner MI, Petersen SE (1990) The attention system of the human brain. Annu Rev Neurosci 13:25-42. CrossRef Medline

Ramalingam N, McManus JN, Li W, Gilbert CD (2013) Top-down modulation of lateral interactions in visual cortex. J Neurosci 33:1773-1789. CrossRef Medline

Rawley JB, Constantinidis C (2009) Neural correlates of learning and working memory in the primate posterior parietal cortex. Neurobiol Learn Mem 91:129-138. CrossRef Medline

Robbins TW (2002) The 5-choice serial reaction time task: behavioural pharmacology and functional neurochemistry. Psychopharmacology 163:362-380. CrossRef Medline

Roelfsema PR, Engel AK, König P, Singer W (1997) Visuomotor integration is associated with zero time-lag synchronization among cortical areas. Nature 385:157-161. CrossRef Medline

Roopun AK, Lebeau FE, Rammell J, Cunningham MO, Traub RD, Whittington MA (2010) Cholinergic neuromodulation controls directed temporal communication in neocortex in vitro. Front Neural Circuits 4:8. CrossRef Medline

Salinas E, Sejnowski TJ (2001) Correlated neuronal activity and the flow of neural information. Nat Rev Neurosci 2:539-550. CrossRef Medline

Sarter M, Hasselmo ME, Bruno JP, Givens B (2005) Unraveling the attentional functions of cortical cholinergic inputs: interactions between signal-driven and cognitive modulation of signal detection. Brain Res Brain Res Rev 48:98-111. CrossRef Medline

Sarter M, Lustig C, Howe WM, Gritton H, Berry AS (2014) Deterministic functions of cortical acetylcholine. Eur J Neurosci 39:1912-1920. CrossRef Medline

Serences JT, Yantis S (2007) Spatially selective representations of voluntary and stimulus-driven attentional priority in human occipital, parietal, and frontal cortex. Cereb Cortex 17:284-293. CrossRef Medline

Shumway, R.H., and Stoffer, D.S (2000) Time series analysis and its applications. New York, NY: Springer.

Stewart C, Burke S, Marrocco R (2001) Cholinergic modulation of covert attention in the rat. Psychopharmacology 155:210-218. CrossRef Medline

Thiel CM, Zilles K, Fink GR (2004) Cerebral correlates of alerting, orienting and reorienting of visuospatial attention: an event-related fMRI study. Neuroimage 21:318-328. CrossRef Medline 
Thiel CM, Zilles K, Fink GR (2005) Nicotine modulates reorienting of visuospatial attention and neural activity in human parietal cortex. Neuropsychopharmacology 30:810-820. CrossRef Medline

Totah NK, Jackson ME, Moghaddam B (2013) Preparatory attention relies on dynamic interactions between prelimbic cortex and anterior cingulate cortex. Cereb Cortex 23:729-738. CrossRef Medline

Turchi J, Sarter M (1997) Cortical acetylcholine and processing capacity: effects of cortical cholinergic deafferentation on crossmodal divided attention in rats. Brain Res Cogn Brain Res 6:147-158. CrossRef Medline

von Stein A, Sarnthein J (2000) Different frequencies for different scales of cortical integration: from local gamma to long range alpha/theta synchronization. Int J Psychophysiol 38:301-313. CrossRef Medline von Stein A, Rappelsberger P, Sarnthein J, Petsche H (1999) Synchronization between temporal and parietal cortex during multimodal object processing in man. Cereb Cortex 9:137-150. CrossRef Medline

Wiley RG, Oeltmann TN, Lappi DA (1991) Immunolesioning: selective destruction of neurons using immunotoxin to rat NGF receptor. Brain Res 562:149-153. CrossRef Medline

Yang FC, Jacobson TK, Burwell RD (2017) Single neuron activity and theta modulation in the posterior parietal cortex in a visuospatial attention task. Hippocampus 27:263-273. CrossRef Medline

Zaborszky L (2002) The modular organization of brain systems. basal forebrain: the last frontier. Prog Brain Res 136:359-372. CrossRef Medline 